\title{
CONTRATUALISMO, UTILITARISMO, A EMERGÊNCIA DO INDIVÍDUO E DA COOPERAÇÃO II: O DIREITO, A POLÍTICA E A ECONOMIA DAS INSTITUIÇÕES DO ESTADO DE DIREITO E DO MERCADO
}

\author{
CONTRATUALISM, UTILITARIANISM, THE EMERGENCE OF THE INDIVIDUAL AND OF THE
}

COOPERATION II: LAW, POLITICS AND ECONOMICS OF INSTITUTIONS OF THE STATE AND OF

THE MARKET

\author{
Carolina Leister \\ José Raymundo Novaes Chiappin **
}

\begin{abstract}
Resumo:
O escopo deste artigo é proceder com a reconstrução racional do programa de pesquisa da política, da economia e do direito como ciência e da abordagem do problema da emergência e estabilidade da cooperação entre indivíduos interagentes. O núcleo central deste programa adota a tese ontológica de que a única entidade real é o indivíduo racional, segundo o modelo de escolha racional, e autointeressado. A heurística é formada da construção de modelos e do método analítico. A reconstrução do programa compõe-se de dois subprogramas relativamente às soluções propostas ao problema: o subprograma contratualista com a construção do Estado de Direito e do indivíduo como pessoa; o subprograma utilitarista com a construção embrionária do Estado Democrático e Social de Direito e do indivíduo como cidadão. O desenvolvimento do programa é progressivo, mas, convive com rupturas de ordem justificativa. A progressividade está na sistemática construção de tecnologia e mecanismo institucional combinando Estado e Mercado. A progressividade caracteriza-se pela transição e evolução do Estado de Direito para o Estado Democrático e Social de Direito. Suas características são a aprendizagem e a flexibilidade para adaptação às mudanças. A compreensão da ruptura entre a justificação e explicação contratualista e a utilitarista depende da relação entre a epistemologia e política.

Palavras-chave: Direito das instituições. Política das instituições. Economia das instituições. A emergência do indivíduo. O problema da cooperação. Contratualismo. Utilitarismo. Estado de Direito. Mercado.
\end{abstract}

\begin{abstract}
:
The aim of the authors is to make a reconstruction of the research program of politics, and of the law as science. This program is split into two subprograms: contractualism and utilitarianism. They are also subprograms of rationalism. The main ontological thesis is that the individual is the only real entity as rational and
\end{abstract}

Professora da Escola Paulista de Política, Economia e Negócios da Universidade Federal de São Paulo. E-mail: carolina.leister@fgv.br.

** Professor Associado do Departamento de Economia da Faculdade de Economia, Administração e Contabilidade da Universidade de São Paulo. E-mail: chiappin@usp.br. 
self-interest. The rationality is expressed by the rational choice model. The main problem is that of the emergence and stability of cooperation among interacting individuals. The solution for the first subprogram is the State of the Civil Rights and the individual as a person. The solution for the second one is the Social and Democratic State and the individual as citizen. The thesis is that on this aspect there is a continual evolution among them. On the other hand there is no continuity in their explanation and justification for the solution. This can be clarified by a relation between epistemology and politics.

Keywords: Politics of institutions. Law of institutions. Economics of institutions. The emergence of individual. The problem of cooperation. Contractualism. Utilitarianism. State of Right. Economics of Market.

\section{Introdução}

O presente artigo tem por objetivo inicial, como desdobramento de outro artigo, ${ }^{1}$ a reconstrução racional do programa de pesquisa da política, do direito e da economia como ciência, enquanto composto de dois subprogramas sucessivos: o contratualista e o utilitarista clássicos. ${ }^{2} \mathrm{O}$ outro objetivo é mostrar que esses subprogramas são progressivos em suas soluções ao problema proposto das condições de emergência e estabilidade da cooperação entre indivíduos interagentes. Há progressividade no sentido de que essas soluções produzem, de modo sequencial, desenhos de mecanismos institucionais complementares cada vez mais complexos e capazes de responder às diversas dificuldades relacionadas com o problema da cooperação. A progressividade do programa convive, porém, com rupturas. Se há progressividade no sistemático aperfeiçoamento da construção do mecanismo institucional, a combinação de Estado com Mercado com a forma democrática de governo, para resolver o problema da emergência e estabilidade da cooperação há, inobstante, ruptura entre as propostas dos subprogramas de justificação e explicação teórica para a solução. A compreensão desses dois aspectos dos subprogramas, progressividade e ruptura, só é possível se for explicitada a pressuposição da relação entre a metafísica, a metodologia e a política, direito e economia, ou seja, entre o programa racionalista e o programa da política, do direito e da economia como ciência. Essa relação já foi explorada em um artigo anterior.

O problema da emergência da cooperação é consequência da emergência do indivíduo, com o estabelecimento por Descartes (DESCARTES, 1966a, 1963)

1 CHIAPPIN, J. R.; LEISTER, C. Experimento mental I: a concepção contratualista clássica, o modelo da tragédia dos comuns e as condições de emergência e estabilidade da cooperação. Hobbes, 2007. Disponível em: $<$ http://escholarship.org/uc/item/3n07b7zq?query=chiappin $>$.

2 LEISTER, C. Social choice \& public choice: o problema da agregação e o cálculo das regras de decisão coletiva como fórmulas de alocação / distribuição de recursos. 2005. Tese (Doutorado) - Faculdade de Filosofia, Letras e Ciências Humanas, Universidade de São Paulo, São Paulo. 
do cogito, como um agente racional e autônomo, como o fundamento ontológico do mundo juntamente com a extensão. Se a extensão é o fundamento ontológico do mundo físico dando origem à elaboração de uma nova imagem do mundo, agora, um mundo mecânico, por outro lado, o indivíduo, como agente racional e autônomo passa a ser o fundamento ontológico de uma nova imagem do mundo político, jurídico e econômico. Hobbes completa o modelo do indivíduo de Descartes com a adição de que se trata de um agente autointeressado e o estabelece como fundamento ontológico de sua concepção do mundo político e jurídico. Hobbes é, portanto, quem desenvolve uma nova imagem do mundo político, jurídico e econômico centrado no indivíduo, no estado de direito, e, nos fundamentos para uma economia de mercado.

Hobbes produz um movimento de ruptura metafísica e metodológica com o mundo aristotélico finito de um cosmo em que cada coisa tem seu lugar natural dando origem a um mundo a ser construído pelo indivíduo racional para constituir um ambiente institucional apropriado no qual possa se desenvolver como um agente racional, autônomo, e autointeressado. Como diria Kant, para que o indivíduo se realize como fim. $\mathrm{O}$ ambiente institucional apropriado contempla o desenvolvimento, segundo os programas do contratualistmo e do utilitarismo, do Estado de Direito e da Economia de Mercado que são entendidas como os melhores desenhos instituições compatíveis com os presumidos direitos dos indivíduos racionais e autônomos emergentes, vida, liberdade, igualdade, e propriedade. A vida sendo o direito supremo e os direitos a liberdade, igualdade, e a propriedade como direitos que garantam o exercício do direito à vida.

A solução do contratualismo para o problema da cooperação entre indivíduos interagentes é uma sistemática construção de um desenho de mecanismo institucional, como se fosse uma tecnologia, cujo núcleo é tanto a concepção do Estado de Direito quanto aquela do indivíduo como pessoa, detentora de direitos e obrigações civis. Ela é feita pela sequência de teorias dos contratualistas como Hobbes, Locke, Rousseau e Kant. A implantação dessa concepção de Estado de Direito para atender à demanda de um novo domínio das relações privais mais compatível também com uma nova forma de relações comerciais mostrou-se cheia de obstáculos.

A história evidencia o recurso à revolução com as revoluções americana e francesa. Isso deslocou o problema, teórico e prático, da emergência da cooperação para aquele da estabilidade. Colocaram-se questões sobre quanto de modificações deveria ter essa concepção e como poderia ser implantada, de modo a aumentar a estabilidade dos mecanismos institucionais da cooperação. A solução do utilitarismo é a construção de um novo desenho de mecanismo institucional como um desenvolvimento e progresso da concepção do Estado de Direito e do indivíduo como pessoa, e uma reinterpretação de sua justificação e explicação teórica. O utilitarismo a completa com uma economia 
de mercado e a organiza com a forma da democracia liberal ${ }^{3}$ de governo. A solução é, agora, um novo desenho de mecanismo institucional que deu origem à concepção do Estado Democrático de Direito e igualmente à concepção do Estado de Direito e Social de Direito, juntamente com a concepção do indivíduo como cidadão, detentor de direitos e obrigações políticos e sociais.

O núcleo do programa da política, do direito e da economia como ciência, conforme já descrito em outro lugar, ${ }^{4}$ tem como componente fundamental três teses ontológicas. A primeira afirma que a única entidade real é o indivíduo como racional e autointeressado. Essa tese é colocada por Descartes (DESCARTES, 1963, 1966a) com o cogito, como mencionado. O modelo de racionalidade é aquela do modelo de escolha racional como também descrito por Descartes nas Regras (DESCARTES, Regra I, 1971). Esse modelo elaborado na separação entre o entendimento e a vontade como faculdades da escolha é central para o desenvolvimento da responsabilidade dos indivíduos por suas ações, e, portanto, pelos fundamentos do direito civil e penal moderno que foi uma das tarefas de Hobbes bem antes de Beccaria.

Essa primeira tese do racionalismo clássico, utilizada pelos contratualistas, dos fundamentos do mundo moderno estar centrado no indivíduo racional e autônomo reflete de maneira mais elaborada a afirmação da tese bastante divulgada do individualismo ontológico e metodológico. A heurística do programa contém o uso de modelos, os quais descrevem os aspectos relevantes dos assuntos a serem abordados, o método de agregação, as hipóteses auxiliares, as técnicas de cálculos, critérios e medidas de escolha social, em particular, o critério de custo e benefício, e, por derradeiro, como seu problema fundamental, o estabelecimento das condições para a coordenação e convivência social, aqui representado pelo problema das condições da emergência e da estabilidade da cooperação entre indivíduos ${ }^{5}$ interagentes. ${ }^{6}$

3 Esse programa de pesquisa, de base liberal, não tem competidor até o século XIX, quando interpretamos como emergindo um programa rival, que é o programa de pesquisa marxista, o qual tem a classe como seu elemento ontológico e outras diferenças metodológicas.

4 CHIAPPIN, J. R.; LEISTER, C. Experimento mental I: a concepção contratualista clássica, o modelo da tragédia dos comuns e as condições de emergência e estabilidade da cooperação. Hobbes, 2007. Disponível em: <http://escholarship.org/uc/item/3n07b7zq?query=chiappin>.

5 CHIAPPIN, J. R. N.; OLIVEIRA, M. The emergence of cooperation among interacting individuals. Physical Review E., v. 59, n. 6, p. 6.419-6.421, 1999.

6 Os artigos a serem desenvolvidos nesse projeto reconstroem as propostas teóricas de Hobbes, Locke, Rousseau e Kant, formando a escola do contratualismo no pensamento político clássico, sob a orientação da qual se deu a construção do Estado de Direito, enquanto Hume, Smith, Bentham, S.-Mill e Sidwick constituem a outra escola clássica, aquela do utilitarismo, crítica da anterior, sob a orientação da qual se deu a construção do Estado Democrático e Social de Direito. O objetivo de uma reconstrução e enquadramento metodológico dessas escolas é a de pretender constituir uma contribuição para o estabelecimento e organização de um quadro conceitual a partir do qual se contextualiza o debate contemporâneo desses mesmos tópicos, em Gauthier, Nozick, Taylor, Rawls, Harsanyi, Binmore, dentre outros. 
A combinação desses instrumentos metodológicos, como os modelos, modelo de escolha racional e o uso dos critérios e medidas de bem-estar, in casu, do critério de custo e benefício, utilizados para abordar os temas mencionados, em particular, o tema da teoria do Estado, poderia ser denominada modernamente como análise econômica do direito. ${ }^{7}$

O subprograma contratualista construiu, como subprograma do racionalismo clássico, tanto o problema da cooperação quanto a primeira solução, que é o Estado de Direito concomitante com a elaboração do indivíduo como pessoa e, por aqui, a temática da relação entre o domínio privado e o domínio público. Com relação a esta última temática, ela é aquela do problema da organização de um sistema jurídico que coordena consistentemente o direito privado com o direito público, de tal modo a promover por meio do Estado a cooperação entre indivíduos interagentes.

Esse subprograma dá origem, com seu núcleo e heurística, ao desenvolvimento de uma sequência de teorias do Estado, como aquelas de Hobbes, Locke, Rousseau e Kant, como propostas para abordar esse problema e a temática, mas, de tal forma, que partilharam de vários compromissos epistemológicos, ontológicos, axiológicos e metodológicos. Uma de suas principais características foi compartilhar uma mesma forma de construir o problema assim como a solução, que é a construção, por meio do contrato, do Estado de Direito e do indivíduo, como pessoa detentora de direitos e obrigações civis. A pergunta fundamental desse subprograma é: por que existe o Estado ${ }^{8}$ e não apenas a liberdade natural, ou seja, por que o autogoverno ou a autotutela não é possível? Qual é a natureza do Estado? E, então, quais as condições para que ele seja possível?

O subprograma utilitarista rejeita a justificativa teórica do Estado de Direito pelos contratualistas, Hume e Bentham ataca a teoria do contrato, mas o aceita, o Estado, como uma das soluções para o problema da cooperação entre indivíduos interagentes. Os utilitaristas rejeitam o uso do contrato originário e dos direitos fundamentais como direitos naturais para tratar do problema da cooperação. O Estado, segundo os utilitaristas, não precisa ser explicado ou justificado teoricamente. Trata-se de um fato histórico que é uma solução para o problema da cooperação não importando suas características exceto que haja poder suficiente para coordenar e sujeitar uma massa de pessoas.

COASE, R. H. The firm, the market and the law. Chicago: The University of Chicago Press, 1988. Esse é o tema de um próximo artigo. Defendemos que a análise econômica do direito nasce com a aplicação do racionalismo clássico para estabelecer a política como ciência. É a análise de Hobbes da explicação e justificação do Estado como solução para o problema da emergência e estabilidade da cooperação social. Ela tem os três ingredientes da análise econômica: modelos, modelo de escolha racional e uma medida de bem-estar social, a de custo e benefício.

8 COASE, 1988. Essa relação entre Hobbes e Coase será tema, igualmente, de um próximo artigo. 
O Estado de Direito é visto como um desenvolvimento histórico e não um Estado originário, o qual é mais bem caracterizado por autoritário. Todavia, inova, ao assumir que também o mercado ou a liberdade civil (e não a liberdade natural) ou o autogoverno é um mecanismo importante para proporcionar cooperação. Eles parecem não se preocupar tanto com o problema da emergência da cooperação, mas, principal e fundamentalmente, em particular o utilitarismo de Bentham, com o problema da estabilidade da sociedade. Aparece com clareza, no quadro teórico do utilitarismo, que a solução para o problema da estabilidade da cooperação deve ser sempre procurada no contex to da combinação desses dois mecanismos institucionais de cooperação: o Estado e o Mercado. A perspectiva da abordagem é igualmente sempre no sentido de propor reformas e não de uma construção nova. Na tentativa de fornecer respostas a esses programas os utilitaristas clássicos, formam também uma sequência de teorias que começa com Hume e Smith e é completada com a de Bentham, Stuart Mill e Sidgwick. Eles serão substituídos pelas concepções de teorias econômicas do bem-estar, iniciando-se com Pigou. ${ }^{9}$

A questão, agora, é sobre que reformas devem ser feitas no sistema institucional, combinando esses dois mecanismos, de tal maneira a torná-lo mais eficiente e mais equitativo. As duas revoluções, americana e francesa, tiveram um impacto muito grande. Eles a interpretaram positivamente como o Estado a ser implantado. No entanto, interpretaram negativamente, quanto ao modo como foi implantado, ou seja, por meio de revoluções. Mas, mais particularmente, pelas consequências associadas com esse modo de implantação, pelo horror e o terror relacionados com a destruição das relações civis, das garantias dos direitos e das vidas humanas. Foi tal o impacto, que redirecionou a preocupação que, com os contratualistas, se referia à emergência da cooperação para aquela da estabilidade. Partiram, portanto, da ideia de que as soluções ao problema da emergência já estavam dadas: o Estado e o Mercado. Como combiná-los? E de que forma implementá-los? Ambas as questões, no contexto do problema da estabilidade da sociedade. Eis o novo problema.

A resposta está na reforma das soluções já admitidas e no redesenho do mecanismo institucional do Estado, de sorte a torná-lo mais eficiente na promoção dos objetivos e mais adaptativo às mudanças. O utilitarismo de Hume e Smith aponta sistematicamente para a ideia de que há mecanismos, que emergem espontaneamente, como o de mercado, capaz também de promover cooperação. Dessa forma, o novo mecanismo institucional que teria maior chance de promover a cooperação era uma combinação da concepção do Estado de Direito com aquela do mecanismo de mercado. A questão tornouse, por conseguinte, como implantar esse desenho de mecanismo institucional que fosse

PIGOU, A. C. The Economics of Welfare. London: Macmillan, 1932. 
composto de um Estado de Direito com o recurso do Mercado, para torná-lo mais eficiente e equitativo na solução do problema da produção e da distribuição da riqueza. ${ }^{10}$

A tese aqui é que esse desenvolvimento institucional é progressivo com a construção pelo utilitarismo, mormente o de Bentham, do Estado Democrático de Direito, e ainda como alternativa o Estado Democrático e Social de Direito como uma combinação do Estado e do Mercado. Bentham constrói sua concepção com a ideia que o principal elemento para tornar esses mecanismos institucionais adaptativos e, por aqui mais estáveis, é adotar uma constituição definindo as funções, estrutura e organização do Estado e a forma democrática de governo.

2. O subprograma do contratualismo e o subprograma utilitarista

A unidade do programa da política como ciência é, não obstante, minimalista em seu conteúdo e, por essa razão, justifica a separação nos dois subprogramas: contratualista e utilitarista. ${ }^{11}$ Outra unidade é ser ele um subprograma do racionalismo. Com essa pressuposição, pretende-se aqui que o desenvolvimento do primeiro é elaborado segundo as diretrizes epistemológicas e metodológicas do segundo. Descartes foi quem elaborou, seguindo o modelo geométrico, a primeira teoria sobre a racionalidade. Uma das teses sobre esse programa é que racionalidade se encontra associada com um método de decisão e de solução de problemas. O modelo de decisão, por sua vez, assume que esta pode ser com certeza ou com incerteza. O modelo com incerteza pode ser objetivo, ou de risco, e subjetivo. O método racional é caracteristicamente decomposto em analítico e sintético. O método guarda relação com os meios para descobrir a base do conhecimento ou para encontrar as ideias intermediárias entre a base e o problema a ser solucionado, e com a organização do conhecimento na forma geométrica como uma teoria ou como um conjunto de modelos.

Como unidade, o programa da política como ciência tem, em seu núcleo, conforme afirmado adrede, teses comuns ao contratualismo e ao utilitarismo. A primeira sustenta que o indivíduo é a única entidade real. A segunda afirma que esse indivíduo é racional e autointeressado. A terceira defende que a racionalidade é descrita pelo modelo da escolha racional. ${ }^{12}$ Como mencionado anteriormente, tais afirmações expressam o que se chama às vezes de individualismo metodológico e ontológico. Na heurística desse

\footnotetext{
10 POLANYI, K. The great transformation. The political and economic origins of our time. London: Beacon Press, 1971.

11 LEISTER, C. Social choice \& public choice: o problema da agregação e o cálculo das regras de decisão coletiva como fórmulas de alocação/distribuição de recursos. 2005. Tese (Doutorado) - Faculdade de Filosofia, Letras e Ciências Humanas, Universidade de São Paulo, São Paulo.

12 VARIAN, H. Microeconomia. São Paulo: Campus, 2007.
} 
programa, encontram-se descritos os instrumentos e metodologias para aplicar o núcleo na solução dos problemas. Os instrumentos são os modelos, métodos de agregação que transformam decisões individuais em decisões coletivas, hipóteses auxiliares, técnicas de cálculos, critérios e medidas de bem-estar social, como o critério de custo e benefício. A ciência, para eles, é uma atividade de resolver problemas. Ela é caracterizada por um método, como um conjunto de regras, de como abordá-los, e de submeter, testar e avaliar objetivamente suas propostas. A metodologia ressalta a elaboração de modelos, representações simplificadas da realidade, ${ }^{13}$ para a solução dos problemas.

O problema central e geral é aquele das condições de emergência e estabilidade da cooperação entre indivíduos interagentes. Os demais fenômenos políticos e sociais são explicados em termos de modelos dos indivíduos em interação. No entanto, o programa da política como ciência terá sua especificidade dependendo do núcleo e da heurística do racionalismo ao qual ele se encontra associado. $\mathrm{O}$ racionalismo fornece as características da ciência. $\mathrm{O}$ contratualismo é um subprograma do racionalismo clássico, e o utilitarismo, do racionalismo neoclássico. Cada um dos subprogramas tem sua especificidade dada pelo seu núcleo teórico e sua heurística.

Se, por um lado, Descartes elaborou a primeira teoria do programa racionalista clássico, com as ideias de que conhecimento é certo, com o modelo geométrico, por outro lado, Hobbes é o artífice, seguindo as diretrizes racionalistas e mecânicas, da elaboração da primeira teoria do subprograma contratualista. Ele definiu a ontologia, a axiologia, a metodologia, a construção do problema, sua solução e seu modus operandi. Ele também seguiu a forma de organização do conhecimento do modelo geométrico. Para Hobbes, na linha do racionalismo clássico, a razão, pelo conhecimento das causas e de suas relações com os efeitos, pode construir mecanismos de intervenção na natureza para obter vantagens de bem-estar e de comodidade para a vida. Com o conhecimento da natureza e da conduta humana, procura-se construir mecanismos para garantir a cooperação entre os indivíduos e promover o seu bem-estar. A sociedade é um produto artificial da razão humana. Hobbes assim o fez, seguindo um método que, para adotar uma nomenclatura moderna, pode ser caracterizado como uma análise econômica do direito.

Hobbes montou uma nova imagem do mundo político, jurídico e os fundamentos da economia de mercado seguindo um raciocínio semelhante ao de Galileu e Descartes e das análises econômicas modernas. Ele fez uso de modelos, como aqueles do estado de natureza e do Estado Civil, do indivíduo como seguindo o modelo de escolha

13 Como foi destacado anteriormente, pode-se notar que há três componentes básicos nessa abordagem: o uso de modelos, o modelo de escolha racional e os critérios ou medidas de bem-estar. Esse conjunto define a análise econômica. O elemento econômico propriamente dito aparece na elaboração das medidas de bemestar. Na abordagem clássica, esse critério é aquele de custo e benefício, das vantagens e desvantagens. Desse ponto de vista, implicitamente, este artigo é uma espécie de análise econômica da teoria do Estado. 
racional, colocado por Descartes, e usou o recurso para tomar decisões, a medida de bemestar assentada em termos de custos e benefícios. O Estado Civil é uma construção da razão que faz avaliações racionais, em termos de custo e benefício.

Do mesmo modo, Hume trouxe de maneira embrionária, e, simultaneamente, os componentes do racionalismo neoclássico, assim como do próprio programa utilitarista. O principal componente do racionalismo neoclássico é a ideia de que a ciência trabalha com hipóteses e não com proposições universais verdadeiras, e que todo conhecimento provém da observação. Consistentemente com essas ideias, o programa utilitarista, com Hume, rejeita o contratualismo, com sua noção de contrato originário e a ideia de direitos naturais. Ele introduz mecanismos naturais de equilíbrio como meios de promover a cooperação, bem como o mecanismo institucional que é o Estado, mas, de agora em diante, não um produto inteiramente construído pela razão humana como queriam os contratualistas. Ele é, antes, um fato social, um produto da evolução da sociedade em suas tentativas e erros para resolver o problema da convivência social. As ideias do modelo geométrico e do conhecimento hipotético, com Bentham, ${ }^{14}$ são completadas com uma teoria dinâmica da convergência para uma teoria ideal, in casu, para um mundo com cada vez menor desigualdade entre os indivíduos, como o eram muitos dos modelos de equilíbrio da época.

Nesse diapasão, diferentemente dos contratualistas, os utilitaristas têm como ponto de partida o mundo real e observável. Ele também é o pressuposto de suas teorias. Em ambos, eles tratam da desigualdade. Eles estão preocupados, sobretudo com a estabilidade e não com cooperação. Trata-se de um fato que as soluções para a cooperação são o Estado e o Mercado. Sob essas condições, o problema é tanto da reforma desses instrumentos quanto das propriedades que devem ter para serem mais eficientes na promoção da cooperação e da estabilidade e como reformar os mecanismos institucionais, de tal modo a torná-los mais efetivos na realização de seus valores e projetos. Quaisquer que sejam esses projetos e valores, o sistema judicial, com Bentham, terá um papel de destaque, porque é com ele, via constituição, que se distribuem os direitos e as obrigações aos indivíduos. Na distribuição dos direitos e das obrigações é que se encontra o principal meio, junto com o poder coercitivo e coativo, à disposição do Estado para garantir a solução do problema da cooperação e da estabilidade.

\footnotetext{
14 Muitos autores utilizam esse modelo de convergência, como Marx, Hegel e Duhem (CHIAPPIN, J. R. N. Duhem's theory of Science: an interplay between philosophy and history of science. 1989. Ph.D thesis University of Pittsburgh, U.S.A. Ann Arbor: University Microfilms International, 1989).
} 
2.1. O subprograma contratualista e a construção do estado de direito

O programa contratualista encontra-se vinculado ao programa do racionalismo clássico. Segue-se que, em seu núcleo, está também o pressuposto ontológico de que o indivíduo racional e autointeressado é a entidade fundamental. Uma das teses importantes deste artigo, que será apenas pressuposta e não argumentada, é que o modelo da racionalidade do indivíduo é aquele do modelo da escolha racional e que seus elaboradores são Descartes ${ }^{15}$ e Hobbes. ${ }^{16} \mathrm{~A}$ tese afirma que o modelo de escolha racional aparece no século XVII e é central no projeto de fazer a política como ciência. O modelo de indivíduo contém o pressuposto ontológico de que seus direitos são inatos. Esses direitos são os direitos à vida, à liberdade e à propriedade. $\mathrm{O}$ programa contratualista é composto de um núcleo e de uma heurística. O uso da metodologia da teoria da ciência (MTC) ${ }^{17}$ para reconstruir esses elementos indica diversas teses ontológicas, epistemológicas e axiológicas que o caracterizam e já foram descritas. As características acima definem um modelo minimalista do indivíduo, não só para o contratualismo, mas para todo o programa da política como ciência.

Todos os fenômenos políticos e sociais devem ser explicados recorrendo-se a esse modelo de indivíduo. O contratualismo segue aqui, com o racionalismo clássico, o atomismo mecânico que pressupunha que as únicas coisas existentes eram corpúsculos com massas em movimento. Todos os fenômenos físicos deveriam ser explicados em termos desses corpúsculos, em suas interações. A ideia é de que conhecimento científico é conhecimento das causas e de suas relações com os efeitos e que deve ser organizado segundo o modelo geométrico. Isso significa o emprego de poucos conceitos e poucos princípios. O objetivo é tirar vantagem, com esses compromissos, da relação entre conhecimento e tecnologia que a nova concepção da ciência incorpora. Tanto a física quanto o contratualismo, com precedência da física, querem fazer uso do conhecimento para construir tecnologias e artefatos, com o objetivo de promover a comodidade e o bemestar social.

A axiologia do contratualismo tem o indivíduo como o seu principal valor e que o faz um fim ${ }^{18}$ e não um meio. Essa tese axiológica pode ser considerada como sua tese suprema. ${ }^{19}$ A estrutura axiológica é elaborada em torno desse valor e conta com três direitos fundamentais que a caracterizam como tal: o direito à vida, o direito à liberdade $\mathrm{e}$

\footnotetext{
DESCARTES, R. Regras para a direção do espírito. Lisboa: Estampa, 1971. p. 13.

HOBBES, T. Leviatã. São Paulo: Abril, 1974. (Coleção Os Pensadores).

17 CHIAPPIN, J. R. N. Racionalidade, decisão, solução de problemas e o programa racionalista. Ciência \& Filosofia, v. 5, p. 155-219, 1996.

18 KANT, I. Fundamentação metafísica dos costumes. São Paulo: Abril, 1974. (Coleção Os Pensadores).

19 POPPER, 1973.
} 
o direito à propriedade. A sociedade é formada de indivíduos, racionais e autointeressados, em interação. Assim, o problema que se coloca, naturalmente, é aquele da emergência e estabilidade da cooperação. O contratualismo fixa esse objetivo como uma das condições para a realização do indivíduo como valor ou como fim. A realização desse valor depende de outro valor, que é o conhecimento da natureza e da ação humana. Não obstante, não se trata aqui apenas de valor teórico e contemplativo. Esse conhecimento pretende ter um valor prático relacionado com a construção de tecnologias e mecanismos de intervenção na natureza voltados para a promoção da comodidade e do bem-estar do indivíduo. Na heurística positiva, tem-se a metodologia e a metametodologia.

$\mathrm{Na}$ metodologia, estão descritos seus métodos de construção, os modelos, as técnicas de cálculo, as hipóteses auxiliares, o método de agregação, os aparatos instrumentais e os critérios e as medidas para fazer escolhas, em particular o critério de custo e benefício. Os modelos comuns ao contratualismo são: o modelo do indivíduo; o modelo do estado de natureza; o modelo do estado de guerra; o modelo do contrato; o modelo do Estado Civil e o modelo da forma de governo. O modelo do indivíduo é aquele do indivíduo como racional e autointeressado. O modelo de racionalidade (DESCARTES, Regra I), é expresso por meio do modelo de escolha racional e formado das faculdades do entendimento e da vontade que constitui o fundamento para a responsabilidade do indivíduo por seus atos e ações.

O modelo do estado de natureza é o modelo composto da interação de indivíduos que são racionais, autointeressados e, além disso, livres, iguais e perseguindo o objetivo de viver por tanto tempo quanto a natureza lhes permita; o modelo do estado de guerra é o modelo da destruição dos indivíduos; o modelo do Estado Civil é o modelo de um poder supremo formado com o consentimento de todos os indivíduos e capaz de coordenar e impor cooperação entre indivíduos com interesses opostos e conflitantes; o modelo da forma de governo é aquele das opções entre a monarquia, aristocracia, democracia.

Um elemento importante da metodologia é o modelo do contrato, o qual é adotado para operacionalizar o método de agregação. O método de agregação é um modelo de transição, de um mecanismo para transformar decisões privadas em decisões coletivas ou de interesses individuais em interesse comum.

Subjacentes a esses modelos, há dois outros - o modelo do domínio das relações privadas e o modelo das relações públicas. No modelo das relações privadas, o indivíduo desenvolve suas relações pessoais, familiares e de negócios, enquanto, no segundo, desenvolve as relações entre ele e o Estado. O primeiro destes é regulado pelo princípio da autonomia da vontade, o segundo é controlado pelo princípio da supremacia do interesse público. Esses modelos estão relacionados com a solução do problema e com a construção do Estado Civil. Outro componente da heurística é a metametodologia. Nela 
se encontram as justificativas que cada autor desenvolve para sustentar sua concepção e as críticas que dirige aos seus rivais, ainda que no mesmo programa. Nesse nível, é possível discutir e analisar, verbi gratia, as críticas de Locke a Hobbes, assim como de Rousseau aos dois anteriores, e assim por diante. Como destacado, a abordagem da política como ciência começa com o controle de seus experimentos, o que significa que o pesquisador tem controle sobre o problema, construindo-o com objetivos razoavelmente claros. A investigação de Hobbes é pela natureza do Estado e do poder político. Por que ele existe? Por que ele é necessário? Qual é sua natureza?

De modo bastante geral, o contratualismo, com os recursos citados, constrói o problema da emergência da cooperação, nas seguintes etapas: (i) Na primeira etapa, assume-se o modelo do indivíduo que é racional e autointeressado. $\mathrm{O}$ modelo da racionalidade é aquele da teoria da escolha racional. A regra da escolha é aquele do benefício líquido, ou seja, de que o indivíduo escolhe sempre a ação que possibilita maximizar os benefícios das suas consequências e minimizar os seus custos. Esses são os elementos que permitem elaborar uma teoria da ação humana. (ii) Nesta segunda etapa, constrói-se o modelo do Estado de Natureza como formador desses indivíduos, mas, agora, em interação. Os indivíduos são racionais e autointeressados a partir do modelo do indivíduo. Como estão em interação, exigem-se propriedades relativas e o modelo pressupõe que são livres e iguais. O modelo do estado de natureza assim descrito é um modelo em que os indivíduos se autogovernam ou se autotutelam em que o domínio das relações privadas coincide com o domínio das relações possíveis entre os indivíduos. $\mathrm{O}$ princípio do comportamento e das relações é aquele da autonomia da vontade.

Na terceira etapa, analisa-se a natureza do modelo, ou seja, a relação entre o modelo do estado de natureza e o modelo do estado de guerra. De acordo com alguns membros do contratualismo, Hobbes e Locke, há razões para que o estado de natureza coincida ou se transforme no modelo de estado de guerra. Para outros, como Rousseau, essa premissa é desafiada e se atribui ao modelo do Estado Civil o modelo do Estado de Guerra. De qualquer modo, os contratualistas constroem, com o uso desses modelos e de forma semelhante aos geômetras, o problema da emergência e estabilidade da cooperação entre indivíduos interagentes.

A ideia de seguir o modelo geométrico, e, portanto, de construir o problema é um ponto extremante importante para a expectativa de fazer da política, e do direito, ciência. O problema é construído de tal maneira a discriminar as variáveis relevantes e controlá-las, para analisar o seu papel e influência. Com a construção do problema, é possível colocar as questões com maior clareza. Questões como, verbi gratia, de por que existe o Estado, e não apenas o autogoverno ou a liberdade natural, e qual é sua natureza. De certo modo, já se sabe a resposta, mas o problema é construído para efeito de 
argumentação e de sustentabilidade científica da resposta. A construção do problema faz parte da prova da solução que pode ser conhecida antecipadamente.

A quarta etapa (iv) é o que se pode denominar modelo de transição, o qual descreve a transição entre a construção do problema e o que contempla a solução. Ele tem a ver aqui com o método de agregação, que é um mecanismo de decisão coletiva. Trata-se de um elemento fundamental na operacionalização da tese ontológica desse subprograma, uma vez que é por ele que se reduzem os fenômenos políticos e sociais às diversas formas de interação entre os indivíduos. O modelo do método de agregação do contratualismo é aquele do instrumento do contrato. No entanto, a relação entre o programa contratualista e o programa do racionalismo clássico é extremamente importante. Isso significa que o método adotado para implementar o projeto da política como ciência é o método racional, em que um de seus componentes é o método analítico-sintético, como Galileu e Descartes o utilizaram.

A construção do contrato é um exercício do método analítico cartesiano de solução de problemas, cujo ponto central é de que ele consiste na busca da ideia intermediária entre duas situações, um modelo sem estado e um modelo com estado. $\mathrm{O}$ modelo sem estado é o modelo do estado de natureza. O modelo com estado é o modelo do estado civil. Esse é o modo científico de estudar a natureza de uma variável, aqui, in casu, o Estado.

A noção do contrato funciona como um mecanismo de escolha coletiva. Ele deve transformar os interesses privados conflitantes dos indivíduos em um interesse comum, o qual constitui a garantia da segurança, da cooperação, e de quais concessões se deve fazer para alcançar esse fim. De acordo com a construção do problema, tem-se que a hipótese de solução é o Estado Civil. Os demais dados são que, no modelo do estado de natureza, os indivíduos são racionais, autointeressados, livres, iguais e querem sobreviver por tanto tempo quanto a natureza lhes permitir.

O modelo do estado de natureza é um modelo sem estado, ou um modelo de estado desordenado e, por aqui, é um modelo do estado de guerra. A consequência do modelo do estado de natureza, como sendo aquele em que há ausência do estado, é a destruição de todos, visto que cada indivíduo tem o direito natural de usar todos os meios, inclusive a vida dos demais indivíduos, para se proteger. Esse direito, nessa perspectiva, funde o modelo do estado de natureza com o do estado de guerra. Esse modelo lembra o modelo de Ising (CHIAPPIN, 1979) para estudar a transição de fase entre um estado desordenado, estado de natureza, e um estado ordenado, o estado civil. Como os indivíduos são racionais e têm expectativas quanto ao futuro, eles antecipam essa consequência para o estado de guerra e, portanto, consideram a possibilidade de evitá-lo. Não obstante, não há incentivo para que cada indivíduo, em particular, procurasse soluções privadas. Ninguém abriria mão de seus direitos, em particular do direito natural à 
autodefesa, a menos que essa fosse uma decisão coletiva. Qual seria, então, o instrumento para fazer transferência de direitos? Qual seria o mecanismo para transformar interesses privados em um interesse comum, por meio de transferência de direito, em um contexto em que prevalece o princípio da autonomia da vontade? O mecanismo institucional do contrato. Em qualquer contrato comum, comercial, trocamos, de maneira geral, direitos de propriedade. Nesse caso, pode-se supor que os indivíduos, racionais, conceberam um contrato pelo qual poderiam decidir, de maneira coletiva, transferir seu direito natural a um terceiro, que seria um sistema de arbitragem, que é o Estado, e também delegar a ele o direito de fazer as regras para sua convivência.

$\mathrm{Na}$ quinta e penúltima etapa (v) se discute a natureza da solução do problema. No modelo do Estado Civil, este é interpretado, para o contratualismo, como uma construção artificial da razão humana. Ele é o produto de um contrato originário, construído com a função e tarefa de garantir a preservação do direito à vida de cada um por tanto tempo quanto sua constituição natural lhe permita. Foi elaborado para perseguir a função de realizar o interesse comum. Se, por um lado, o direito à vida é o direito de cada um, por outro lado, como resultado do contrato, a obrigação de cada um é observálo. Cada um deve abster-se de fazer qualquer ação que atente contra ele. A garantia da preservação do direito à vida é feita ao custo de concessões, em seus direitos naturais, à propriedade e à liberdade. Nas particularidades a respeito desse trade-off de direitos, têmse diferentes concepções do Estado.

A passagem do modelo de um Estado desordenado para um modelo de Estado ordenado é feita por meio do contrato como produto da razão humana. Esse Estado ordenado é realizado pela construção de uma tecnologia, que é o estado civil, tendo por propósito o benefício da preservação do domínio das relações privadas. Nesse domínio, seriam assegurados, dependendo da concepção do Estado, os direitos, não mais naturais, mas civis, como os direitos à vida, à liberdade e à propriedade. $\mathrm{O}$ modelo de Hobbes da transição do estado de natureza para o estado civil é uma antecipação, mantendo as devidas proporções, do modelo de Ising (CHIAPPIN, 1979) sobre a emergência da cooperação.

Concomitantemente, esse indivíduo emerge, com o Estado Civil, com direitos civis, por conseguinte, positivos, de sorte que não é mais um indivíduo, mas uma pessoa com direitos e obrigações. A pessoa tem o direito fundamental, um direito subjetivo, de recorrer ao poder do Estado para proteção de seus direitos. O significado de ser uma pessoa é que agora ele tem o poder, o direito de reivindicar a presença e o poder do Estado, na proteção desses seus direitos civis. Esse é o benefício de ter feito um trade-off com seus direitos naturais: a proteção de alguns de seus direitos civis requer a limitação de outros. Isso só é possível com a transformação dos direitos naturais em direitos positivos, com a construção de um mecanismo artificial que os distribui. O custo da construção de um novo domínio das relações privadas é ser ele, agora, menos extenso 
e mais limitado do que no Estado de Natureza. O custo da preservação desse domínio é o da construção do domínio das relações entre o Estado e o indivíduo que é aquele do direito público, a partir de uma cisão do domínio originário que é eminentemente privado, e, que o reduziu em suas extensões.

O novo domínio emergente pela construção do Estado para resolver o problema da cooperação é necessariamente aquele das relações entre o Estado e o indivíduo. Esse novo domínio de relações vai ser regulado pelos princípios da legalidade, como controle do indivíduo sobre o Estado, e o da supremacia do interesse comum, determinando que o interesse comum prevalece sobre o interesse individual, ou seja, que o interesse comum não pode ser privatizado. A estrutura do Estado com esses dois domínios, princípios associados e os direitos civis, é o Estado de Direito, e o indivíduo, como seu membro, é, agora, uma pessoa, sujeito de direitos e obrigações, em que um dos direitos, é o de requer a tutela jurisdicional do Estado para seus direitos. O indivíduo tem o direito de provocar o Estado para a proteção de seus direitos. O Estado de Direito é uma tecnologia que foi construída para exercer essa função de coordenador da cooperação entre interesses privados conflitantes. Trata-se de uma organização hierarquizada, portanto, diferente das relações no estado de natureza. A hierarquização provém do fato de que a organização estatal conta com o monopólio da força. É a soma do consentimento de todos os indivíduos, logo, um poder superior a todos os demais sob seu domínio. É com esse poder que se dá a implementação da garantia do direito à vida, pelo princípio da supremacia do interesse público.

Por sua vez, o desenho do mecanismo institucional se sofistica (LOCKE, 1983 ) para poder controlar a si mesmo. Ele deve ser o mais eficiente possível na realização de sua tarefa e evitar que se desvie dela, que é a garantia dos direitos individuais. Ele é controlado, portanto, pelo princípio da divisão do exercício do poder e pelo princípio da legalidade. Esse quadro mais completo do Estado de Direito não é aquele de Hobbes. A natureza do Estado, no contratualismo, é que ele é uma tecnologia produzida pela razão humana. O Estado é construído como um meio termo entre, por um lado, total liberdade natural, a anarquia, e, por outro lado, a submissão natural, que é a alternativa da época com o direito divino dos reis. O modelo do Estado Civil é, antes de qualquer coisa, como Estado de Direito, como um mecanismo de composição de conflitos e de construção da cooperação, um sistema de arbitragem construído pelos próprios indivíduos.

Na sexta etapa (vi), analisa-se o modelo das formas de governo, no qual se verifica para cada um dos membros da concepção contratualista as razões para se adotarem esta ou aquela forma de governo. A argumentação desses autores em defesa de uma forma de governo em lugar de outra é muito importante, no desenvolvimento do programa de pesquisa contratualista. 
O programa é formado de sequência das teorias de Hobbes, Locke, Rousseau e Kant. Elas representam uma contribuição de progressividade na construção do Estado de Direito e do indivíduo como pessoa.

A primeira solução é a de Hobbes, com sua concepção de Estado Absoluto. A solução de Hobbes não é o que caracteriza seu subprograma, mas sua metodologia e seus princípios. A metodologia está na construção do problema, do modo como abordálo ao estilo geométrico e da física de Galileu. Os recursos metodológicos e heurísticos, juntamente com os pressupostos sobre o indivíduo e o Estado como solução para o problema da cooperação, formam os elementos básicos de todas as teorias do Estado de Locke, de Rousseau e de Kant. Esse conjunto constitui o que denominamos aqui de um programa de pesquisa. Hobbes tem por objetivo fazer da política ciência, seguindo o método racionalista do programa racionalista como construído por Descartes. O método racionalista é uma abstração relacionada com a mecânica de Galileu e o modelo geométrico como dado pelas aplicações de Descartes. Esse método permite, pelo conhecimento que dá da natureza, como afirma Descartes, conquistá-la e dominá-la. Com isso se pode fazer construção de tecnologias. Elas possibilitam ao homem aumentar o seu bem-estar social.

Com esses instrumentos, Hobbes aborda o problema de por que existe o Estado ou qual é sua natureza, além de pensar na construção de tecnologias. No entanto, diferentemente de Galileu e Descartes, o estudo de Hobbes é sobre a natureza e a ação humana. As instituições seriam as tecnologias a serem construídas, assim como do conhecimento da ótica se pretende construir lentes e lunetas. Hobbes estuda a natureza e a ação humana e suas interações no melhor estilo da abordagem da ciência e do procedimento analítico. Hobbes faz uso de modelos simplificados do indivíduo e das relações entre eles, modelos os quais são os mesmos como aqueles do plano inclinado de Galileu e o da gota de chuva de Descartes. Ele faz, como Galileu e Descartes, experimentos mentais como orientação para experimentos reais. Hobbes pretende, com suas construções mentais, entender a realidade da sociedade. Em particular, as condições para cooperação entre indivíduos com as características da racionalidade e do autointeresse, a natureza do Estado, e, sobretudo, da legitimidade do poder político, por que os indivíduos lhe devem obediência e não vivem apenas pelo princípio da autonomia da vontade.

Hobbes constrói os principais aspectos do programa do contratualista. Ele elabora um modelo simplificado do indivíduo como racional e autointeressado. Ele assume que a racionalidade é dada de maneira semelhante à do modelo de escolha racional. Descartes igualmente o descreveu como esse modelo. ${ }^{20}$ Adverte-se que, para Hobbes, o indivíduo não nasce racional, porém, aprende a sê-lo com a descoberta da linguagem, a

${ }_{20}$ DESCARTES, R. Regras para a direção do espirito. Lisboa: Estampa, 1971. p. 13. 
qual seria uma das primeiras tecnologias. Hobbes faz uso, seguindo os passos de Galileu e Descartes, de um conjunto básico de modelos para construir o problema do mesmo modo como um geômetra.

Hobbes coloca, num quadro teórico semelhante ao de Galileu e Descartes, a questão de por que existe o Estado e de qual é sua natureza. A resposta a essa questão demanda, seguindo o roteiro desse quadro teórico, o desenvolvimento de modelos básicos que, in casu, são os dois já mencionados modelo do Estado de natureza e o modelo do Estado Civil. Como descrevemos, o primeiro deles é o modelo de um Estado de Natureza como um modelo sem Estado. Esse modelo é formado de um conjunto de indivíduos, segundo o modelo do agente racional, em interação. Pressupõe-se que os indivíduos nesse estado são livres e iguais e têm o propósito de viver tanto tempo quanto a constituição natural lhes permita. Como tais, eles se valem do princípio da autonomia da vontade humana e do princípio do direito natural, que significa fazer uso de todas as coisas, inclusive tirar a vida do outro para se proteger.

Segundo Hobbes, o desenvolvimento lógico desses pressupostos é de que a natureza do Estado de Natureza, com liberdade natural, é o Estado de Guerra. Para ele, o modelo do Estado de Natureza e o Estado de Guerra se fundem. Os agentes racionais que levam em conta suas expectativas, mormente no que diz respeito à sua sobrevivência, antecipam essa consequência do Estado de Guerra e sua autodestruição e também as suas causas. Hobbes, como Galileu com respeito à física, quer ainda conhecer as causas da ação humana, para poder controlá-la. Ele identifica uma dessas causas no direito natural de se autoproteger com o uso da força física e com o direito à vida do outro. Outra é que os interesses privados são conflitantes e não há incentivo no Estado de Natureza, para que espontaneamente os indivíduos se alienem ou desistam de seus direitos $\mathrm{O}$ custo dessa alienação privada é a própria vida. Certamente, há um interesse comum, que é aquele das condições de segurança para uma sobrevivência duradoura. Como são agentes racionais, escolhem ações que lhes proporcionam vantagens, como essa da realização do interesse comum das condições de segurança.

A questão teórica consiste em definir qual seria a situação que lhes deveria trazer vantagens mútuas ou recíprocas, no que diz respeito às condições de segurança. Como construí-la? A solução já existe. Ela é o Estado Civil. Mas, qual é sua natureza? Por que ele existe? Qual é sua função? A solução deve estar restrita aos dados do problema e seguindo o método racional dos filósofos da natureza. Se os indivíduos têm as propriedades descritas e consequentemente se comportam sempre para realizar seu autointeresse, como fazê-los cooperar e conviver? Estabelecer regras de convivência social e garantir que elas sejam obedecidas.

A questão da garantia para que as regras sejam obedecidas é solucionada pela construção de um poder superior ao poder de quaisquer dos subgrupos da sociedade. 
Essa é a natureza do Estado. Estado é um poder que tem por função a garantia do direito à vida como o interesse comum. Ela representa a soma do consentimento de todos para a realização dessa tarefa, que se fosse realizada por autotutela teria um custo muito mais alto que poderia ser a própria autodestruição. Sob as condições dos dados do problema, ele é também um produto da razão humana decorrente do estudo e compreensão da natureza, da ação humana e de suas relações. Essa é igualmente sua natureza, ou seja, uma tecnologia. Qual seria o instrumento pelo qual os indivíduos, por si mesmos, seguindo o princípio da autonomia da vontade humana, chegariam a essa compreensão de manifestar um interesse comum e de operacionalizá-lo?

Esse instrumento é o contrato. O contrato é um meio natural de criar um interesse comum a partir de interesses privados e mesmos conflitantes. Indivíduos racionais estariam propensos a fazer um contrato apenas na medida em que ele apresenta vantagens mútuas. A questão da garantia da sobrevivência para cada um é um interesse comum o qual apresenta vantagens mútuas. Todavia, por que seria necessário o Estado, se os indivíduos são racionais? Se a relação entre a geometria e a ciência da ação humana é como menciona a passagem de Hobbes:

There is a great similitude between that we call injury, or injustice in the actions and conversations of men in the world, and that which is called absurd in the arguments and disputations of the Schools. For as he, that is driven to contradict an assertion by him before maintained, is said to be reduced to an absurdity; so he that through passion doth, or omitted that which before covenant he promised not to do, or not to omit, is said to commit injustice. And there is in every breach of covenant a contradiction properly so called. $^{21}$

Então, por que o Estado? Porque, em termos epistemológicos, entre a razão e a vontade existem as paixões. No racionalismo, o método racional emergiu para dominar e submeter a vontade à direção da razão. Como o modelo dos agentes é o modelo da escolha racional, conforme descrito por Descartes, e a vontade deve seguir rigorosamente o que o entendimento lhe mostra, é imperioso que ela seja uma vontade racional. Mas, e se ela estiver submetida às circunstâncias das paixões? Eis Hobbes, Locke, Rousseau e Kant. O Estado de Direito é uma solução provisória para fazer com que os indivíduos se sujeitem às leis, enquanto não se encontram em uma situação na qual a razão não é mais escrava das paixões. Assim, o Estado deve ser construído como uma tecnologia, a partir do conhecimento da natureza humana, como solução provisória para ajudar a realizar a convivência social e proporcionar bem-estar social. Para Descartes, como para Hobbes,

${ }_{21}$ HOBBES, T. The elements of law. London: Frank Cass, 1969. p. 82. 
conhecer cientificamente a natureza é poder manipulá-la, de modo a fazê-la servir às comodidades da vida humana. ${ }^{22}$

A construção da segunda teoria do Estado por Locke se faz pela tentativa de abordagem dos problemas que foram deixados pela concepção de Hobbes. Ele faz uso dos mesmos princípios do núcleo e dos mesmos recursos da heurística do programa da política como ciência. Por isso, a tese é de que Locke, Rousseau e Kant são considerados membros do programa contratualista construído por Hobbes. No entanto, os teóricos estão cientes de que a solução hobbesiana tem uma miríade de dificuldades, entre as quais a de que o Estado Absoluto é externo à sociedade e não está submetido às leis que ele mesmo cria, de sorte que não há razão para que, antes de ser garantia da segurança, não seja também e ainda uma ameaça. No raciocínio de Hobbes, qualquer poder menor que o Estado Absoluto, quer dizer, qualquer limitação do seu poder gera uma instabilidade que o leva de volta ao Estado de Natureza. Não obstante, o Estado Absoluto de Hobbes que soluciona o problema da cooperação não deve ser confundido com o Estado da monarquia absoluta do direito divino dos reis. Esse ponto é central. Hobbes pretende desenvolver uma concepção de Estado como solução para o problema da cooperação que se afaste por um lado do estado de natureza, mas, que, por outro lado, não se confunda com o Estado do direito absoluto dos reis fundado no direito divino como ele mencionado em sua introdução ao Leviatã (HOBBES, 1973).

A aceitação do Estado como Estado Absoluto é, assim, feita sob a ideia de que sem ela a alternativa é o Estado de Natureza como Estado de Guerra. O Estado Civil como Estado Absoluto, com sua garantia ao direito à vida, é sempre melhor do que a última alternativa, pois com ela, pratica-se a autodestruição. A ameaça real do Estado Absoluto ao direito de liberdade e ao direito de propriedade não pareceu a Locke ser um trade-off justo para a garantia do direito à vida. Era preciso a endogeinização do Estado. A questão, agora, para Locke, depois de Hobbes, não era mais de por que existe o Estado, mas, antes, se poderia pensar na construção de outro sistema de instituições, uma tecnologia mais apurada que redesenhasse o Estado, de modo a garantir esses três valores assumidos como direitos naturais inalienáveis.

O objetivo de Locke é refinar a solução de Hobbes da construção do Estado Civil como um Estado Liberal de Direito. Ele deveria garantir não apenas o direito à vida, mas também à liberdade e à propriedade. Na construção dessa solução, Locke utiliza o mesmo aparato metodológico hobbesiano, inclusive o mecanismo do contrato como

\footnotetext{
22 Ressalta Hobbes:

The end or scope of philosophy is, that we may make use to our benefit of effects formerly see; or that, by applications of bodies to one another, we may produce the like effects of those we conceive in our mind, as far forth as matter, strength, and industry, will permit, for the commodity of human life... (HOBBES, T. The elements of law. London: Frank Cass, 1969. p. 7).
} 
instrumento, para fazer a transição entre os dois modelos básicos que são o Estado de Natureza e o Estado Civil. O instrumento do contrato é logicamente consistente com a ênfase, por esses autores, no domínio das relações privadas e de sua preservação com a sua regulamentação pelo princípio da autonomia da vontade. No entanto, Locke combina componentes metodológicos, agora, de uma forma diferente, de tal forma que o Estado a ser construído como uma organização institucional reflita seus valores que caracterizarão o Estado Liberal de Direito.

Locke parte do mesmo modelo básico do indivíduo, não obstante, considerando que os indivíduos já nascem racionais, autointeressados, adiciona o direito natural à vida de Hobbes, os direitos naturais à liberdade e à propriedade. Redefine também o Estado de Natureza, transformando-o em um estado ideal, o qual é um estado em que os indivíduos, por serem racionais, seguem a lei da natureza que os proíbe de prejudicar os demais. Tal montagem do Estado de Natureza permite que Locke o considere como um estado de harmonia e tranquilidade. Nesse estado, os indivíduos perseguem suas relações privadas, como as relações pessoais, familiares e comerciais, segundo apenas e tão somente o princípio da autonomia da vontade com os direitos à vida, à liberdade e à propriedade. Esse é o domínio de puras relações privadas. Todavia, seria esse Estado de Natureza estável? E, se não, qual é a razão? Ela estaria no sistema natural de composição de conflitos que não é eficiente.

O Estado de Natureza tem para Locke um sistema natural de composição de conflitos. A ele cabe julgar as transgressões à lei da natureza e aplicar as penalidades. Esse sistema natural depende da lei natural que regularia o comportamento dos indivíduos e das relações entre eles. A lei natural é, não obstante, interpretada por ele como uma norma, e não uma lei física. Isso significa que sua necessidade pode não se dar, se a razão estiver submetida às paixões. Nesse caso, não deve existir lei sem uma sanção (externa) a ela associada. Esse sistema natural de composição de conflitos é constituído de todos os indivíduos nesse Estado, a humanidade. Todos os indivíduos, isoladamente, são juízes e executores da lei natural. Assim, quando se dá uma transgressão à lei da natureza, pois, nem sempre se pode estar de plena posse da razão, e nem evitarmos sermos assaltados pelas paixões, esse sistema é acionado. Uma vez dada a transgressão, o transgressor encontrase, por conseguinte, em um Estado de Guerra relativamente aos demais indivíduos. Ele deve ser julgado por esse sistema natural.

Esse sistema, porém, se revela com muitos problemas, visto que ele não é impessoal nem imparcial, de sorte que cada indivíduo pode julgar conforme seus interesses e aplicar penalidades, que, sob essa ótica, são frequentemente desproporcionais à transgressão. Em remate, não é um sistema eficiente e apropriado para a recuperação do equilíbrio e da estabilidade perdida com a transgressão. Destarte, o Estado de Guerra pode se propagar e desestabilizar todo o Estado de Natureza. 
Para evitar tal consequência, demanda-se a construção de uma organização institucional, como o Estado. Ele tem a tarefa de realizar o interesse comum, que é o de instaurar um sistema imparcial e impessoal de composição de conflitos. Ele deve ser um tribunal institucional para estabilizar a ordem natural do Estado de Natureza, que é aquela das relações privadas reguladas pelo princípio da autonomia da vontade, de maneira a preservar os direitos naturais à vida, à liberdade e à propriedade.

Seguindo essa linha de raciocínio, vê-se que Locke está questionando por que existe o Estado e qual é sua natureza, a construção de um Estado com condições mínimas para a preservação e restauração do Estado de Natureza. Isso seria feito com o mínimo de intervenção no Estado de Natureza. Essa intervenção mínima seria aquela da construção de um mecanismo institucional, com a finalidade de ser um efetivo sistema de composição de conflitos. A efetividade dependeria de ser construída de maneira imparcial e independente. Assim, a função principal do Estado é a de produzir leis e de aplicá-las, para que se preserve o domínio das relações privadas, com o princípio da autonomia da vontade e os direitos naturais. O Estado Liberal de Direito não tem outra função senão a de estar a serviço dos indivíduos para a garantia desses direitos.

Com Locke, como com Hobbes, o objetivo é construir mecanismos institucionais, um sistema de composição de conflitos, de modo a garantir que o Estado não tenha outra função que garantir os direitos individuais. Esses recursos institucionais devem ser tais que sejam responsáveis pela construção, aplicação e controle das regras as quais regem a relação entre os indivíduos, logo, com o direito privado, e de regras que orientam a relação entre os indivíduos e o Estado, portanto, com o direito público. Nesse contexto, o Estado não pode ter, para Locke, senão três poderes: legislativo, executivo e federativo.

Não se trata de uma divisão de poderes, mas, de uma divisão no exercício do poder, o qual é sempre uno no Estado. Essa divisão funciona como um sistema de pesos e contrapesos e tem por finalidade evitar abusos de suas funções. O legislativo tem a função de criar e elaborar as leis, enquanto o executivo e o judiciário, considerados por Locke como um único (que é executivo), são responsáveis pela sua aplicação. O poder federativo dá ao Estado os meios de proteger o país das ameaças externas. As leis e regras referem-se ao direito privado e ao direito público. $\mathrm{O}$ direito privado tem como princípios organizadores o princípio da legalidade e o princípio da autonomia da vontade. Ele regula o domínio das relações privadas dos indivíduos com seus direitos. O direito público regula as relações entre o indivíduo e o Estado e tem como princípios o da supremacia do interesse público sobre o privado e o princípio da legalidade.

Como custo pela criação do Estado, relativamente ao Estado de natureza, o domínio das relações privadas se cinde em dois domínios, um domínio menor, para as relações privadas, e o domínio das relações públicas. Locke coloca, diferentemente de 
Hobbes, o predomínio do domínio das relações privadas relativamente àquela do domínio das relações públicas. A construção do domínio das relações públicas deve representar as condições mínimas para preservar o domínio das relações privadas.

No que tange às formas de governo, Locke não defende uma forma particular, no entanto, tudo indica que apoiou a monarquia constitucionalista por refletir o seu ponto de vista, que é aquele de um Estado Liberal de Direito descrito adrede. Outro elemento importante do racionalismo é que faz uso de teorias para explicar a realidade. A teoria política de Locke assume que os indivíduos são iguais e livres, no Estado de Natureza. Com esses pressupostos, ele deverá responder por que os indivíduos, no mundo real, são desiguais em termos políticos e sociais.

O problema da desigualdade é um problema que nasce com Hobbes uma vez que ele estabeleceu como um dos pressupostos do modelo do estado de natureza que os indivíduos são iguais. Desde que o mundo real mostra inequivocamente que os indivíduos não estão numa situação de desigualdade cabe à teoria explicar como a desigualdade se desenvolveu a partir do estado de natureza no qual eles se encontravam em situação de igualdade. Portanto, discutir qual é a origem dessa desigualdade e, também, se ela é desejável ou deve ser eliminada é elemento central de todas as teorias pós Hobbes, e, portanto, é um dos principais, senão o principal problema da nova imagem do mundo composta por Hobbes e os demais teóricos do contratualismo e utilitarismo.

Como consequência da lógica de sua construção, Locke procura demonstrar ou explicar que a desigualdade real entre os homens na vida se dá no Estado Natural e que ela é uma desigualdade natural e não civil. A razão é o aparecimento da propriedade e do dinheiro. Tal problema, da desigualdade, por sua vez, será o problema que Rousseau deverá tratar e ao qual responderá de maneira diferente de Locke. É ponto de partida para Rousseau construir ainda uma teoria contratualista. Em Rousseau, o Estado deve expressar a soberania de todos os indivíduos e, por aqui, explicar que a desigualdade tem sua origem no Estado Civil e não no Estado de Natureza, portanto, que o contrato mal feito que produziu esse Estado Civil deve ser refeito. Por revolução ou reforma? Kant faz a opção de um progresso pelo qual se chega ao domínio do reino dos fins, que é o domínio da liberdade, com o progresso da razão e da transformação da vontade na vontade racional com o controle das paixões. O Estado é um instrumento provisório para essa condução. Kant constrói o fundamento teórico da concepção contratualista. Ele é o reino dos fins, em que o único princípio a prevalecer é o da autonomia da vontade. A concepção de Kant é um desenvolvimento teórico e lógico da afirmação de Hobbes $^{23}$ de que há equivalência

23 HOBBES, T. The elements of law. London: Frank Cass, 1969. p. 82. 
entre o método de redução ao absurdo com aquele da quebra do contrato por um indivíduo racional.

O fio condutor político do contratualismo é o princípio da autonomia da vontade. Ele é um princípio liberal, sempre preservado na construção do Estado de Direito. O Estado de Direito é construído, exatamente, para garantir que o indivíduo, com seus direitos naturais, usufrua de forma duradoura, pelo tempo que a natureza lhe permita, do maior domínio possível das relações privadas segundo esse princípio. Prevalecendo esse princípio, o Estado deve encolher. Não obstante, a extensão é determinada pelo custo da garantia de seus direitos. O custo é dado pela extensão do domínio das relações públicas? A relação entre os dois domínios serve de diretriz para a construção institucional do Estado de Direito. A axiologia das concepções vai determinar essa relação.

No contexto da ideia de que um indivíduo racional não pode quebrar contrato, tem-se que a cisão do domínio das relações privadas é provisória com a construção do Estado. A construção do Estado faz encolher o domínio das relações privadas. O objetivo é gradativamente ir eliminando o domínio das relações públicas, pelo aperfeiçoamento dos indivíduos como pessoas, com o controle de suas paixões pela razão, até tornar possível um retorno ao Estado de Natureza de Locke. Tal parece ser a lógica interna do contratualismo que prioriza o domínio das relações privadas. Nesse contexto, o Estado de Direito tem uma função eminentemente provisória de ajudar a conduzir os indivíduos a controlar as paixões e readquirir o pleno domínio da razão e, nessas circunstâncias, dispensar o Estado.

Essa é a linha de desenvolvimento teórico que se pressupõe aqui como guiando a sucessão das teorias de Hobbes, Locke, Rousseau e Kant. Em outros termos, o desenvolvimento progressivo do subprograma do contratualismo clássico de Hobbes a Kant se dá pela contínua compatibilização do princípio da autonomia da vontade e aquele da supremacia do interesse público. No reino dos fins, que é o da liberdade, o interesse comum se confunde com o interesse privado. A compatibilização vai sendo construída por meio da elaboração do conceito de liberdade do indivíduo, que é a expressão, com Kant, da vontade racional. O indivíduo é livre, na medida em que segue o princípio da autonomia da vontade, o qual consiste em dizer que "[a] autonomia da vontade é aquela sua propriedade graças à qual ela é para si mesma a sua lei”. ${ }^{24}$

Dessa forma, o desdobramento dedutivo desses pressupostos sobre as características ontológicas dos indivíduos racionais leva à afirmação de Kant de que o indivíduo é fim e nunca meio. A razão pela qual o Estado é construído é que os indivíduos se reconhecem, no Estado de Natureza de Hobbes, como fins, com seus direitos à vida,

${ }_{24}$ KANT, I. Fundamentação metafísica dos costumes. São Paulo: Abril, 1974. p. 238. (Coleção Os Pensadores). 
à liberdade e à propriedade. No entanto, eles ainda não são reconhecidos, uns pelos outros, como fins. Cada indivíduo, no Estado de Natureza de Hobbes, se reconhece a si mesmo como fim, porém, ainda é meio para os demais. O reconhecimento objetivo é produto da astúcia da razão que, de maneira estratégica, constrói o Estado de Direito como instrumento para realizar esse reconhecimento.

O Estado é, assim, um meio a que os indivíduos recorrem para que se realizem como fins, significando viver de acordo com a lei da liberdade, isto é, segundo o princípio da autonomia da vontade. Esse princípio teórico e abstrato, de que os seres racionais são fins, encontra-se manifestado de maneira concreta na ideia de que os direitos fundamentais são direitos inatos. Ela encontra-se explicitada na ideia lançada inicialmente por Rousseau de que o Estado e o Governo devem resultar de uma operacionalização possível da Vontade Geral, a qual emerge da autonomia da vontade.

Tais princípios levamnecessariamente às demandas de sua operacionalização. Eles pressionam para a adoção do sufrágio universal com o direito de todos de votar e ser votado e, portanto, para a escolha da forma democrática de governo e, outrossim, para a forma republicana de Estado, ou seja, que se deve ter um governo de leis. Essa pressão pode ser realizada por meio de revoluções ou de reformas. O programa utilitarista procurará desenvolver uma estratégia de realização desse fim com a construção de um desenho de Estado que evite as revoluções.

As duas formas de Estado e de Governo, federação e república com sufrágio universal, parecem ser uma maneira efetiva de expressar o conteúdo da conciliação entre os princípios da autonomia da vontade e da supremacia do interesse público. São elas igualmente as formas mais efetivas tanto para que se exerça o princípio de que os indivíduos são sempre fins e não meios, quanto para que se promova e se aperfeiçoe sistematicamente esse princípio. Kant seria a síntese teórica dos elementos teóricos do ideário político liberal do contratualismo clássico, enquanto a construção histórica do Estado e do Governo dos Estados Unidos, expressa na Constituição americana, como uma democracia e uma federação, seria uma aplicação política e social desse ideário. A constituição francesa e a tentativa de construir a forma de governo da França como República seria outra realização prática dessas ideias. Ressalta Kant, sobre o princípio de que o homem é fim e não meio:

Ora, digo eu: - O homem, e, duma maneira geral, todo o ser racional, existe como fim em si só como em si mesmo, não só como meio para o uso arbitrário desta ou daquela vontade. Pelo contrário, em todas as suas ações, tanto nas que se dirigem a ele mesmo como nas que se dirigem a outros seres racionais, ele tem sempre que ser considerado simultaneamente como fim. [mais adiante] Seres racionais estão, pois, todos submetidos a esta lei que manda que cada um deles jamais se trate a si mesmo ou aos outros 
simplesmente como meios, mas sempre simultaneamente como fins em si mesmos. ${ }^{25}$

É importante notar que a forma democrática de governo parece emergir naturalmente como, talvez, a melhor maneira de expressar, exercitar e operacionalizar os princípios mencionados no ideário liberal do contratualismo, porém, a democracia não é apresentada e justificada, por seus membros, exceto talvez por Rousseau. A realização do contratualismo é mais bem associada à construção do Estado de Direito e do indivíduo como detentor de direito e obrigações civis. Seu núcleo são as ideias: (i) o Estado é o governo das leis; (ii) o Estado foi construído, pela razão, para proteger os direitos fundamentais; (iii) o Estado é adstrito por esses direitos interpretados como direitos inatos; (iv) os direitos fundamentais são os direitos à vida, à liberdade e à propriedade. Seus princípios vão sendo elaborados para compor, em torno do princípio da autonomia da vontade, o princípio da supremacia do interesse público e o princípio da legalidade. $\mathrm{O}$ contratualismo não está associado à construção do Estado Democrático de Direito, o qual incorpora junto aos direitos civis os direitos políticos e, muito menos, ao Estado Democrático e Social de Direito, que é um Estado dos direitos civis, políticos e sociais. Essa é a realização do utilitarismo.

\subsection{O subprograma utilitarista e o estado democrático e social de direito}

A transição do racionalismo clássico para o neoclássico com Hume é seguida pela mudança do subprograma contratualista para o utilitarista, também com Hume. O racionalismo neoclássico se caracterizaria por uma concepção antimetafísica e por suas duas versões, uma moderada e outra radical. A concepção do racionalismo neoclássico radical seria denominada convencionalismo ou instrumentalismo, com fortes tonalidades relativistas e céticas. Este rejeita qualquer valor objetivo para as teorias científicas e enfatiza apenas seu valor organizacional, instrumental e classificatório. $\mathrm{O}$ método de testes empíricos não é capaz de escolher ou rejeitar uma teoria em termos conclusivos. Os nomes associados a essa concepção são Hume e, mais tarde, Poincaré. Porém, o radicalismo de Hume seria ainda maior, no sentido de que sua concepção de ciência refletiria muito mais o método experimental do que aqueles relacionados com o estilo teórico de fazer ciência, como o modelo geométrico. Seu modelo seria mais a Ótica de Newton do que os Principia.

A transição do racionalismo clássico para o racionalismo neoclássico tem superposição com a transição do subprograma do contratualismo para o do utilitarismo.

$25 \quad$ KANT, I. Fundamentação metafísica dos costumes. São Paulo: Abril, 1974. p. 228 e p. 233. (Coleção Os Pensadores). 
O subprograma utilitarista rejeita várias das teses do contratualismo. Suas teses epistemológicas são opostas. O compromisso epistemológico do contratualismo com o racionalismo clássico, com sua ideia de conhecimento certo, proporcionou as condições para sustentar as teses dos direitos naturais e do contrato originário como origem do Estado, além da ideia de que o Estado é uma construção da razão humana.

A substituição, com o racionalismo neoclássico, do conhecimento certo pelo conhecimento hipotético e sua adoção da tese de que todo conhecimento provém da experiência determinam a importância dos testes e experimentos empíricos para a avaliação das teorias. Os utilitaristas seguem sua influência, ao estudar os fenômenos sociais. Eles rejeitam as teses dos direitos naturais, do contrato originário e de que o Estado é uma construção artificial, produto da razão humana.

A epistemologia impõe restrições em sua abordagem dos problemas políticos e sociais. Os problemas políticos e sociais, com a presença das revoluções e suas consequências da instabilidade social, da guerra civil, da destruição em massa, das sistemáticas transgressões dos direitos que reivindicavam implantar, colocam a questão de se pensar em alcançar os mesmos objetivos, pelos quais as revoluções foram feitas, porém, com reformas regulares e sistemáticas, a partir da concepção do Estado de Direito. Consequente com seus compromissos epistemológicos e metodológicos do racionalismo neoclássico, a concepção utilitarista rejeita a ideia do Estado como uma construção da razão humana e a substitui pela ideia de que o Estado é um fato social e um componente da promoção da cooperação entre os indivíduos.

Os utilitaristas não perguntam por que existe Estado e qual é sua natureza. Eles o consideraram um fato e um dos componentes na promoção da paz social. Não obstante, eles afirmaram, como um elemento inovador, que existiam mecanismos naturais os quais promoviam a cooperação em vários aspectos das interações entre indivíduos. A cooperação poderia ocorrer como resultado de um mecanismo de equilíbrio comum, nas situações de interação entre agentes, como, verbi gratia, o mecanismo de equilíbrio da balança comercial, como o mercado de transações de bens, como o mecanismo que produz a sincronização entre diversas pessoas remando em uma canoa. Interpretaram do mesmo modo o fato histórico da existência do Estado Civil. Ele teria evoluído num processo adaptativo para uma situação de coordenação e sincronização de interesses conflitantes em direção a um interesse comum.

Os contratualistas tinham mostrado que os contratos de transação envolviam vários institutos jurídicos, entre os quais o instituto jurídico da propriedade. Sob essa ótica, Locke justifica que o direito de propriedade é um direito natural. Assim, no contrato original, transacionavam-se direitos de propriedade e, portanto, logicamente era preciso garantir que existia direito de propriedade como direito natural, para dar plausibilidade às transações contratuais no domínio das relações privadas. Os utilitaristas consolidaram 
a ideia de que a cooperação era o produto natural de uma evolução adaptativa, que foi selecionando seus dois principais promotores, o Estado e o Mercado. Entretanto, a questão era a propósito da melhor forma de organizá-los em um mecanismo institucional que os combinasse, para que se permitisse uma maior eficiência e outrossim, e mormente, estabilidade.

O problema se deslocou, por conseguinte, sobretudo para a questão da estabilidade da cooperação. $\mathrm{O}$ impacto dos fatos políticos e sociais provocado pelas revoluções trouxe esse problema à tona, pois havia quase um consenso em torno da solução pelo Estado de Direito. O resultado dessa reflexão foi a elaboração, pelos utilitaristas, de uma concepção reformista do Estado, o qual foi sendo construído como um mecanismo institucional formado da combinação da economia de mercado com uma democracia liberal. Tal combinação transformou o Estado de Direito e do indivíduo como pessoa. Essa transformação foi feita para evitar o recurso da revolução para sua implantação. A transformação que leva a um processo de implantação sistemático e gradual é aquela no Estado Democrático de Direito ou Estado Democrático e Social de Direito, e o indivíduo como cidadão, que significava um cidadão um voto. Segundo eles, esse mecanismo institucional seria mais adaptativo às mudanças que estavam se sucedendo na sociedade. A forma de governo da democracia seria um elemento fundamental para a estabilidade.

As diferenças dos compromissos epistemológicos entre os utilitaristas e os contratualistas implicam diferenças no modo de abordar cientificamente os problemas da política e, talvez, em diferenças nas concepções políticas. Relativamente à solução dos contratualistas para a cooperação, que é o Estado, a contrapartida dos utilitaristas é que é a liberdade civil, e não a liberdade natural, a que promove a cooperação com o mecanismo de mercado. Hume e Smith chamaram a atenção para o uso do mecanismo de mercado, de sorte a promover de maneira espontânea a cooperação. Ambos rejeitam a solução proposta de que a emergência da cooperação é realizada por um contrato, construído por uma tecnologia produzida de maneira deliberada pela ciência. Hume rejeita explicitamente, assentado em suas premissas epistemológicas e metodológicas, a versão contratualista de que há um contrato original. ${ }^{26}$

Para eles, a cooperação entre os indivíduos interagentes é fruto de uma técnica, mas uma técnica semelhante a um artefato, gerado por um processo sistemático, evolutivo e regular de aprendizagem, do tipo learning by doing. O mercado é a expressão mais paradigmática de tal artefato. Ele é capaz de produzir, por um processo de

26 HUME, D. Ensaios morais, políticos e literários. Rio de Janeiro: TopBooks, 2004; Ensaio XII. Do contrato original, p. 672: "Afirmo que as questões humanas nunca permitirão esse consentimento e raramente algo que se aproxime dele; e que a conquista ou a usurpação, ou mais simplesmente a força, por meio da dissolução dos antigos governos, estão na origem de quase todos os governos que o mundo já viu nascer”. 
coordenação natural, cooperação entre os agentes, que são racionais e autointeressados. Assim, indivíduos racionais e autointeressados, quando em interação, não precisam gerar uma solução destrutiva e de perda para todos, como queria Hobbes, no seu modelo do Estado de Natureza. Ao contrário, para Hume e Smith, indivíduos racionais e autointeressados, em interação, podem produzir, com muito menos controle racional das paixões e com dotações iniciais, um interesse comum, verbi gratia, o preço de mercado e uma nova alocação, que consistiria em uma situação (alocação) em que todos melhoram relativamente à situação anterior àquela das trocas coordenadas pelo mercado. Nessa concepção utilitarista, o Estado emerge igualmente, porém, naturalmente, por evolução e não como uma construção planejada e decorrente de uma avença originária, como um meio de resolver o problema da cooperação e de sua estabilidade.

O subprograma utilitarista de Hume e Adam Smith afirma, como mencionado, que não é o mecanismo do contrato, mas o mecanismo de mercado ${ }^{27}$ que funciona como método de agregação para fazer emergir o consentimento. Ele é descrito por Adam Smith como uma mão invisível. ${ }^{28}$ Hume o apresenta como um mecanismo do equilíbrio da balança comercial. ${ }^{29}$ Hume recorre outrossim à metáfora sobre remadores de um barco, ${ }^{30}$ cuja sincronização emerge de maneira gradual e naturalmente equilibrando o barco numa direção precisa. Essa direção é a solução de um processo repetido, de tentativa e erro, de coordenação impulsionada pelo sentido do interesse dos agentes, todavia, sem o recurso de promessas e dos compromissos mútuos. A tese metodológica aqui é de que o mercado, que é um mecanismo natural, transforma os interesses privados em um interesse comum. Ele faz emergir um consenso.

Esses autores têm como pressuposição a crença de que uma organização e uma coordenação do social são bem melhor servidas pela cooperação espontânea

27 LEISTER, C. Social choice \& public choice: o problema da agregação e o cálculo das regras de decisão coletiva como fórmulas de alocação/distribuição de recursos. 2005. Tese (Doutorado) - Faculdade de Filosofia, Letras e Ciências Humanas, Universidade de São Paulo, São Paulo.

28 Citamos Adam Smith (2002, p. 226): "São conduzidos por uma mão invisível a fazer quase a mesma distribuição das necessidades da vida que teria sido feita, caso a terra fosse dividida em porções iguais entre todos os seus moradores; e assim, sem intenção, sem saber, promovem os interesses da sociedade, e oferecem meios para multiplicar a espécie".

29 HUME, D. Ensaios morais, políticos e literários. Rio de Janeiro: TopBooks, 2004; estabelece uma analogia entre o comércio exterior e a hidrostática dos vasos comunicantes, para mostrar que há um mecanismo para manter o equilíbrio na balança comercial.

30 Hume afirma: "Two men, who pull the oars of a boat, do it by an agreement or convention, tho' they have never given promises to each other" ( A treatise of human nature. London: Oxford University Press, 1980. p. 490). Essa metáfora tornou-se um exemplo de jogos de coordenação que servem para mostrar como emergem convenções, encontrando-se associada a outros modelos de jogos, verbi gratia, àquele derivado da ilustração de Rousseau e denominado Stag Hunt, como faz Skyrms (2004), e ao dilema do prisioneiro frequentemente associado, como neste artigo, com a proposta de Hobbes para resolver o problema da cooperação por meio de um agente externo. 
dos indivíduos, cada um realizando seu autointeresse. ${ }^{31} \mathrm{~A}$ ideia seria que quanto menos intervenção e quanto mais natural fosse o processo de interação, entre indivíduos procurando realizar seu autointeresse, mais a cooperação funcionaria em benefício do interesse coletivo, de maneira mais eficiente. Segundo eles, as relações construídas pelos indivíduos, que são as instituições, não devem distorcer essas interações naturais, mas, antes, incorporá-las, organizá-las em uma estrutura externa, não obstante, a elas adaptadas. A instituição política e social do sistema jurídico da common law, o direito consuetudinário, de tradição inglesa, seguiria essa concepção e é uma das suas melhores expressões. No entanto, como já mencionado, eles aceitam como um fato que o Estado é um agente de coordenação e de cooperação.

A despeito da força da tradição utilitarista de Hume e Smith, há uma segunda linha do utilitarismo, mencionada adrede, na qual constam, entre seus membros, Bentham e Sidgwick. Essa tradição, enquanto utilitarista, partilha das duas características citadas, da rejeição à ideia dos direitos naturais ${ }^{32}$ e do contrato original. ${ }^{33}$ Porém, divergem quanto à ideia, cara aos outros utilitaristas, de que a construção das instituições políticas deveria se adaptar e completamente moldada pelos padrões e regularidades políticas e sociais, que naturalmente emergem da evolução natural das interações entre os indivíduos. A forma do sistema jurídico do direito consuetudinário, common law, seria a melhor expressão. No entanto, eles rejeitam essa concepção do direito e adotam a concepção do código.

Bentham difere dos utilitaristas mencionados anteriormente, em termos metodológicos, quanto à forma de organização do conhecimento e sobre o papel político e social do Estado. Ele se aproxima aqui dos contratualistas, no sentido de um papel ativo

31 Para iluminar a interpretação subjacente ao problema da cooperação para cada um dos subprogramas, contratualismo e utilitarismo, podemos supor que o primeiro estrutura esse problema nos mesmos termos daquele expresso pelo dilema do prisioneiro one-shot e, ipso facto, exige um agente externo para regular, coordenar ou afiançar a cooperação, a qual não emerge naturalmente em uma única rodada, dada a estrutura do dilema do prisioneiro. O último, o utilitarismo, toma-o como um problema de coordenação ou, para dizer o mínimo, como o dilema do prisioneiro iterado, portanto, como uma questão de ajustes empreendidos marginalmente nas estruturas institucionais políticas cooperativas que naturalmente emergem da interação humana. As diferenças adrede apontadas podem ser justificadas em função de os contratualistas construírem dedutivamente as condições de possibilidade da emergência da cooperação, ao passo que para os utilitaristas - e também para Hume, cuja teoria os inspira -, a cooperação é avaliada sob uma perspectiva dinâmica.

32 BENTHAM, J. The works of Jeremy Bentham. Bowring, John. Bristol: Thoemmes Press, 1843. v. 2, p. 501. "Natural rights is simple non-sense: natural and imprescriptible rights, rhetorical nonsense, -nonsense upon stilts".

33 BENTHAM, J. The works of Jeremy Bentham. Bowring, John. Bristol: Thoemmes Press, 1843. v. I, p. 268: "As to the Original Contract, by turns embraced and ridicule by our Author [Blackstone], a few pages, perhaps, may not be ill bestowed in endeavoring to come to a precise notion about its reality and use. The stress laid on it formerly, and still, perhaps, by some, is such as renders it an object not undeserving of attention. I was in hopes, however, till I observed the notice taken of it by our Author, that this chimera had been effectually demolished by Mr. Hume. I think we hear not so much of it now as formerly. The indestructible prerogatives of mankind have no need to be supported upon by sand foundation of a fiction". 
e intervencionista para o Estado. A rejeição do contrato por Bentham é feita em termos fortes, como se pode ver pela passagem seguinte:

The origination of government from a contract is a pure fiction, or in other words, a Falsehood. It never has been known to be true in any instance; the allegation of it dos mischief, by involving the subject in error and confusion, and is neither necessary nor useful to any good purpose. ${ }^{34}$

Bentham é um utilitarista, todavia, um pouco diferente de Hume e Smith. Uma das razões que o levam a ser diferente é sua adesão a certos princípios metodológicos mais característicos do contratualismo. A organização do conhecimento para Bentham é similar àquela do modelo geométrico comum, ao contratualismo. Os estudos de Bentham sobre a linguagem, que o levaram à construção da teoria das ficções como um método de construção da teoria jurídica, têm suas raízes em Descartes, com suas ideias sobre a gramática universal. Eles podem, igualmente, ser associados a Hobbes e seu uso da linguagem para a construção da teoria científica ${ }^{35}$ e, principalmente, a Locke. ${ }^{36}$ Entretanto, não devemos, por outro lado, esquecer que o uso da linguagem serve, outrossim, ao propósito, assim como o é para Hume, de demarcar sua reflexão filosófica da metafísica, rejeitando termos sem significados, quer dizer, que não dão origem a consequências relacionadas à experiência.

Outra diferença entre os dois utilitarismos é que o de Bentham rejeita também a solução contratualista, sem o fazer apenas e tão somente pela substituição pelo mecanismo de mercado. Segundo a concepção de Hume e Smith, o Estado deveria promover a cooperação, seguindo a liderança do mercado. Para eles, o domínio das relações privadas, governadas pelo mercado, deveria ser o mais amplo possível. Não parece ser essa, porém, a concepção de Bentham para o papel do Estado. Bentham entende que o Estado é o meio, com o mecanismo de mercado, de promover consentimento a partir dos interesses privados. Mas, o Estado o faz por intervenção. Entretanto, o elemento inovador de Bentham é o modo pelo qual Estado deve promover consentimento por intervenção.

Bentham propõe uma teoria da ação coletiva, um estudo científico da ação do Estado. A ação do Estado, em suas intervenções, deve ser conduzida pelo princípio da utilidade, o qual é a sua solução ao método de agregação. Ele é um meio de introduzir objetividade na ação do Estado. A utilidade é um método de agregar as ações individuais em ações coletivas. Trata-se de um algoritmo de cálculos, tanto por parte dos

34 BENTHAM, J. The works of Jeremy Bentham. Bowring, John. Bristol: Thoemmes Press, 1843. v. 2, p. 501. 35 HOBBES, T. op. cit., 1974.

36 LOCKE, J. Segundo tratado sobre o governo. São Paulo: Abril Cultural, 1983. (Coleção Os Pensadores). p. $227-270$. 
indivíduos quanto por parte do Estado. Enquanto instrumento do Estado para promover consentimento, o algoritmo seria um importante instrumento de políticas públicas. No entanto, ele não é apenas um princípio global, mas, igualmente, um princípio local, sendo o princípio da ação individual. $\mathrm{O}$ indivíduo age sempre no sentido de maximizar seus benefícios, representados por seu prazer, de sorte a minimizar seus custos, constituídos pela dor.

O princípio da utilidade coletiva ${ }^{37}$ é apresentado como a soma das utilidades dos indivíduos. O indivíduo, para ele, é também considerado como racional e autointeressado. Sua racionalidade é uma racionalidade de cálculos, de custo e benefício, reduzidos a prazer e dor. Bentham define o princípio da utilidade como sendo ainda um princípio local, que é o da racionalidade da ação humana. Conforme a tese empirista, a ação humana deve ser um comportamento observável, portanto, reduzido a elementos empíricos, como a busca do prazer e a rejeição da dor. ${ }^{38}$ Ela é a mesma racionalidade do indivíduo de Hobbes, no Estado de Natureza, o qual faz igualmente cálculos em termos de custo e de benefício. A racionalidade é o fundamento de sua teoria, tanto da ação individual quanto da coletiva. O princípio da utilidade é uma manifestação da tese empirista de que todo conhecimento provém da experiência e, que, ipso facto, nosso conhecimento geral é sempre hipotético, já que sua avaliação é pelas consequências.

A adoção do princípio da utilidade como princípio da ação coletiva significa que o Governo teria de promover a maior felicidade para o maior número. ${ }^{39}$ Isso quer dizer, por sua vez, de maneira intermediária, como se verá mais tarde, promover objetivos sociais, como segurança, igualdade, subsistência e abundância da comunidade. A realização desses objetivos seria a condição primeira e básica para a promoção da cooperação e de sua estabilidade. A promoção da segurança, ${ }^{40}$ por seu turno, é valor fundamental e pré-condição para realizar os três outros objetivos, a saber: subsistência, abundância e igualdade. ${ }^{41}$

Bentham propõe algumas estratégias, ligadas com sua crítica às restrições contratualistas, para abordar o problema da estabilidade da organização social. A primeira dessas estratégias é a elaboração do Estado de direito como uma forma democrática de governo e os indivíduos como dotados de direitos políticos e sociais. Os indivíduos como

37 BENTHAM, J. The works of Jeremy Bentham. Bowring, John. Bristol: Thoemmes Press, 1843. v. 1, p. 1721, p. 301.

38 BENTHAM, J. The works of Jeremy Bentham. Bowring, John. Bristol: Thoemmes Press, 1843. v. 1, p. 1. "Nature has placed mankind under the governance of two sovereign master, pain and pleasure".

39 BENTHAM, J. The works of Jeremy Bentham. Bowring, John. Bristol: Thoemmes Press, 1843. v. 1, p. 1-2.

40 BENTHAM, J. The works of Jeremy Bentham. Bowring, John. Bristol: Thoemmes Press, 1843. v. 1, p. 303. Como assevera Bentham: "In legislation, the most important object is security".

41 BENTHAM, J. The works of Jeremy Bentham. Bowring, John. Bristol: Thoemmes Press, 1843. v. 1, p. 302307. 
pessoas passam a ser, igualmente, cidadãos para participar dos negócios do Estado. A segunda estratégia é que essa construção seria feita dentro de um conjunto de regras, princípios e valores expostos com clareza, por meio do estabelecimento de um sistema jurídico codificado e hierarquizado, o qual consistiria em um código constitucional, no qual estariam definidos os fins, a organização e a estrutura do Estado e sua forma de governo. Esse código constitucional articularia, como uma estrutura hierarquicamente superior, o Direito Civil e o Direito Público com seus ramos.

A terceira estratégia desenvolve aquela da primeira, na medida em que adiciona aos direitos civis os direitos políticos de votar e ser votado e os direitos sociais, como aqueles da igualdade, além do direito à segurança, o qual garantiria os direitos civis, como o direito à vida, à liberdade e à propriedade. Bentham menciona explicitamente que os direitos sociais são aqueles referentes à igualdade, à subsistência e à abundância. O Estado teria uma intervenção positiva relativamente a esses direitos, no sentido de promover as condições para o seu exercício. O resultado da composição dessas três estratégias é a construção embrionária do Estado Democrático e Social de Direito.

A primeira dessas estratégias diz respeito à forma democrática de governo. Ela é adotada por Bentham, de forma explícita, como central para a moldura do Estado com poder de reformas. A forma democrática de governo é elemento-chave de sua concepção para realizar a aplicação de seu princípio da utilidade. Segundo esse princípio, o objetivo do governo é proporcionar a maior felicidade para o maior número possível da comunidade. O maior número aqui é dado pelo voto majoritário, em que cada homem corresponde um voto. Com esse recurso, elegem-se e se instituem os representantes para realizar os valores também colocados pelo voto majoritário. A forma democrática de governo é expressa do modo implícito no princípio da utilidade como o condutor do comportamento do governo na escolha das políticas públicas, ou seja, "[...] the sole object of government ought to be the greatest happiness of the greatest possible number of the community". 42

A segunda estratégia de Bentham consiste na elaboração de um sistema jurídico. Um sistema compatível, segundo ele, com um dos princípios fundamentais da democracia e do direito público, que é o princípio da publicidade. Esse sistema jurídico deveria ser, nesse caso, um sistema codificado de leis. A compatibilidade com o princípio da publicidade requer como propriedades do sistema a transparência e a acessibilidade pelos usuários. São razões substanciais, então, que fazem com que Bentham mantenha

${ }_{42}$ BENTHAM, J. The works of Jeremy Bentham. Bowring, John. Bristol: Thoemmes Press, 1843. v. 1, p. 301. 
uma cruzada contra a defesa, por Blackstone, do direito consuetudinário, ${ }^{43}$ e não, como quer Richard Posner, as leviandades de vender constituições. ${ }^{44}$

A construção do sistema judicial codificado deve ser articulada em torno de um código constitucional, com os objetivos de definir os fins, a organização, a estrutura do Estado e sua forma de governo, in casu, a democracia. Para Bentham, a concepção do direito como direito codificado e positivo é a melhor forma para se elaborar uma concepção de Estado capaz de se adaptar às mudanças e reagir efetivamente aos seus desafios. Ela é igualmente a maneira mais compatível com os princípios básicos da democracia, em particular com o princípio da publicidade. ${ }^{45}$

Nesse contexto, ficam claras igualmente as razões de sua crítica aos direitos fundamentais como direitos naturais. Ele adota a concepção do direito como direito positivo. O direito deve ser um sistema estatal de regras com recurso, pelo Estado, de coerção e coação, portanto, um sistema convencional de regras. Com a ideia de democracia vem junto a rejeição dos direitos inatos. Cabe à sociedade negociar, por meio de regras, os valores e o conjunto de regras aos quais ela deve se submeter. Além disso, que a forma de governo seja a democracia é absolutamente essencial. Que o consentimento seja dado pelo sufrágio universal é a única maneira de promover a construção de um poder capaz de não ser contraposto por nenhum outro. Este é o meio de evitar o recurso da revolução para promover as reformas demandadas pelas mudanças que ocorrem na sociedade.

Bentham enfatiza que o sistema jurídico deve proporcionar os meios legítimos de o Estado levar a cabo e operacionalizar suas políticas públicas e sua capacidade de intervenção para realizar as reformas e estabilizar a realização dos valores, a fim de fazer frente às mudanças da sociedade e às consequentes demandas políticas e sociais. A intervenção por meio de políticas públicas se encontra nas mãos do legislador e da legislação. Um desses meios está associado à distribuição dos direitos e obrigações aos membros da sociedade. A distribuição dos direitos e obrigações faz parte do estabelecimento das condições para a realização do fim colocado pelo uso do princípio da utilidade como princípio da conduta do Estado, que é o de prover a maior felicidade para o maior número. Bentham deixa isso muito claro, quando assevera: "Every thing which the legislator is called upon to distribute among the members of the community, may be reduced to two classes: $1^{\text {st }}$, Rights. $2 \mathrm{~d}$, Obligations." ${ }^{46}$

A importância do sistema jurídico cresce ainda mais, na caracterização do papel intervencionista do governo, segundo Bentham, na medida em que a distribuição

43 BENTHAM, J. The works of Jeremy Bentham. Bowring, John. Bristol: Thoemmes Press, 1843. v. 1, p. 220295.

44 POSNER, R. The economics of justice. Cambridge: Harvard University Press, 1983. p. 35.

45 BENTHAM, J. The works of Jeremy Bentham. Bowring, John. Bristol: Thoemmes Press, 1843. v. 2 , p. 310.

46 BENTHAM, J. The works of Jeremy Bentham. Bowring, John. Bristol: Thoemmes Press, 1843. v. 1, p. 301. 
de direitos e obrigações deve se submeter aos objetivos de garantir à comunidade, como direitos, segurança, igualdade, abundância e subsistência. Isso será feito, não obstante, conforme diretrizes que preservariam uma hierarquia axiológica, de acordo com a qual se atribui à segurança ${ }^{47} \mathrm{o}$ objetivo principal e, depois, à igualdade.

A característica social desses objetivos faz com que, para Bentham, o sistema judicial trate igualmente de direitos e obrigações sociais, além dos direitos políticos. Com a concepção de Estado que promova os direitos políticos e sociais, tem-se concomitantemente a transformação do indivíduo como pessoa com direitos e obrigações civis no cidadão com direitos e obrigações políticas e sociais. Essa relação entre os direitos e obrigações e os objetivos que condicionam e ajudam na busca da felicidade é claramente sustentada na seguinte passagem:

In this distribution of rights and obligations, the legislator, we have already said, should have for his object the happiness of the body politic. In inquiring more particularly in what his happiness consists, we find four subordinate objects-Subsistence. Abundance. Equality. Security. The more perfect enjoyment of all these particulars, the greater the sum of social happiness, and especially of that happiness which depends upon the laws. ${ }^{48}$

Os utilitaristas rejeitam o artificialismo dos contratualistas, com a ideia de um Estado de Natureza no qual os indivíduos são livres e iguais. O ponto de partida dos utilitaristas, devido a seus compromissos fortemente empiristas, é a observação da sociedade real com suas desigualdades e ausências de liberdade. Com a ideia de uma dinâmica social, eles elaboram uma concepção que parte da sociedade real com suas desigualdades e tem por objetivo a diminuição sistemática e gradativa dessa desigualdade, de sorte que possa se transformar em uma sociedade na qual prevaleça a igualdade. Esse movimento da desigualdade para a igualdade deve ser conduzido por um desenho de Estado que pode ser gradativamente reformado, em lugar de implantar um Estado pronto por meio de revoluções. A ideia de dinâmica social, de uma concepção convergentista, a qual conduziria a uma sociedade ideal é o modelo de progresso social do século XIX, com Duhem, Hegel e Marx. Bentham também o adota, na busca de um igualitarismo. Eles são uma resposta a como implantar o reino ideal dos fins de Kant, por meio de reformas e adaptações evitando as revoluções.

O subprograma utilitarista aborda, com essas ideias, a relação entre o princípio da autonomia da vontade e o princípio da supremacia do interesse público do governo no domínio das relações privadas e das relações públicas. No entanto, não

47 Id. Ibid., v. 1, p. 303: "In legislation, the most important object is security".

48 Id. Ibid., v. 1, p. 302. 
o faz de modo homogêneo. No utilitarismo de Hume e Smith, o viés é pelo princípio da autonomia da vontade como em Locke. O Estado intervém apenas para a proteção dos direitos básicos. O utilitarismo de Bentham tem o viés do princípio da supremacia do interesse público, com a concepção de um Estado capaz de promover intervenções políticas e sociais e, por aqui, fazer frente às mudanças da sociedade, evitando, por essa estratégia, a solução via revolução.

A manifestação mais clara dessa construção adaptativa do Estado é de ser ela realizada por meio de uma nova forma de sistema jurídico já mencionado adrede. Tratase, não obstante, de um sistema jurídico elaborado com o recurso de uma constituição. A constituição define a função, a estrutura e a organização, e os valores do Estado e os princípios gerais, organizando as relações entre os indivíduos, o direito privado, e aqueles organizando as relações entre os indivíduos e o Estado, o direito público. A constituição organiza hierárquica, consistente e harmonicamente o direito público e o direito privado. Na constituição de uma sociedade, deveriam estar representados os seus valores, sua axiologia social e política, seus propósitos e os meios, direitos e obrigações de que está disposta a fazer uso, para realizá-los. Em remate, na constituição é que a sociedade se posicionaria sobre a relação entre esses dois princípios. Lá estaria igualmente expresso o viés relativamente a um ou outro dos dois princípios. Mais ou menos Estado.

$\mathrm{O}$ utilitarismo de Bentham encontra no sistema judicial um dos meios para a intervenção do Estado, a fim de promover uma busca assintótica do igualitarismo a qual depende, por sua vez, de considerar como supremo objetivo a segurança. Isso é explicitamente afirmado por Bentham:

We may observe, that in a nation which prospers by agriculture, manufactures, and commerce, there is a continual progress towards equality [...] Hence we may conclude, that security, by preserving its rank as the supreme principle, indirectly conducts to the establishment of equality. ${ }^{49}$

Nessa passagem está sua ideia de uma dinâmica social em busca do igualitarismo. Na teoria do conhecimento da época se pretendia buscar a teoria ideal, que representaria a realidade, pela substituição sistemática das teorias provisórias, todavia, cada vez mais abrangentes e profundas, de modo a aproximar de uma teoria verdadeira. Da mesma forma, seria possível interpretar a concepção de Bentham sobre as teorias da organização social e seus objetivos. Elas partem do que se observa, que é a desigualdade e a ausência de liberdade real entre as pessoas. Essas teorias deveriam, assim, preocuparse em propor meios de construir mecanismos institucionais que permitissem conduzir a

49 BENTHAM, J. The works of Jeremy Bentham. Bowring, John. Bristol: Thoemmes Press, 1843. v. 1, p. 313. 
sociedade para uma situação de sistemática e gradativa diminuição da desigualdade como o fim de um processo.

Nesse diapasão, Bentham é crítico da afirmação de que os homens nascem livres e iguais, como se estabelece na Declaração Universal dos Direitos. ${ }^{50}$ Para ele, a liberdade não está no ponto de partida, mas no final do processo social e político. Os homens não nascem nem iguais e nem livres, mas têm expectativas de se tornar iguais e livres. Deve-se aperfeiçoar e construir novos mecanismos institucionais que cooperem na realização desses fins. Nesse diapasão, afirmamos que Bentham tem uma concepção teleológica da sociedade compatível com o modelo de dinâmica que é padrão no século XIX. Mas, por outro lado, o princípio da autonomia da vontade não é abolido do sistema de Bentham. Ele está sempre presente e põe limite à intervenção do Estado, determinando sua abrangência. ${ }^{51}$

A reforma política do Estado, tendo o sistema judicial como seu principal instrumento, é, com Bentham, uma estratégia de construção embrionária do Estado Democrático e Social de Direito. Esse Estado é o que melhor garante as condições para sustentar uma coordenação e estabilidade da cooperação social. A opção pela reforma política requer em si mesma uma reforma que impõe a adoção da democracia como forma de governo, a qual requer uma ampliação dos direitos civis dos indivíduos herdados do Estado de Direito. Os novos direitos associados à reforma política, para o estabelecimento da forma democrática de governo, são aqueles referentes aos direitos políticos, como o direito de votar, de ser votado, da liberdade de expressão, da liberdade de imprensa... etc.

Nesse novo conjunto de direitos é que se define a natureza do Estado Democrático de Direito. Com o acréscimo dos direitos sociais e a ampliação do papel do Estado para promovê-los, chega-se à concepção do Estado Democrático e Social de Direito e do indivíduo como cidadão. Eles são direitos que envolvem uma participação direta e intervencionista do Estado. Esse é um raciocínio decorrente de um desdobramento lógico da aplicação do princípio de utilidade que demanda a maior felicidade para o maior número como princípio da ação coletiva ou do Estado.

Segue-se que a importância do princípio da utilidade não é apenas de permitir organização lógica para a concepção de Bentham a qual atribui à presumida racionalidade dos agentes uma maior operacionalidade. Ele é, outrossim, um princípio substancial que acaba por exigir do agente coletivo, in casu, o Estado, um conteúdo social. Como demanda do governo compromisso com a busca da maior felicidade para o maior número, ele

$50 \quad$ Id. Ibid., v. 2, p. 498-499.

51 Como salienta Bentham: "The care of providing for his enjoyments ought to be left almost entirely to each individual; the principal function of government being to protect him from sufferings" (Id. Ibid., v. 1, p. 301). 
pressupõe igualmente um conteúdo político com proposta de que a democracia deve ser a forma de governo e os indivíduos serem cidadãos, portanto, com direitos civis e sociais. O princípio da utilidade traz ainda mais efetividade na caracterização da racionalidade dos agentes. Ele completa as características quantitativas do modelo da escolha racional que é a expressão dessa racionalidade. A utilidade ajuda a quantificar o aspecto subjetivo da escolha que inclui o lado dos desejos e das preferências que põem os fins.

A operacionalidade do modelo da escolha racional é fundamental para a construção de instrumentos objetivos para a escolha e elaboração de políticas públicas, como para a inteligibilidade do processo de escolha por parte dos indivíduos e, por aqui, de suas demandas. Tem-se um tratamento mais analítico e científico à intervenção do governo e à avaliação dos seus instrumentos de intervenção. Com isso, permite ao Estado, com seus recursos escassos, levar a cabo reformas políticas e sociais blindado dos interesses privados e das ideologias. Ele possibilita um estudo objetivo do comportamento e da ação humana, em suas decisões de alocação de seus recursos. Em acréscimo, ele confere objetividade às escolhas públicas como escolhas das melhores alocações dos recursos entre os diversos membros da sociedade.

O Estado Social e Democrático de Direito encontra, com Pigou, ${ }^{52}$ a elaboração de instrumentos mais refinados e poderosos de intervenção. Por intermédio de Pigou, começa-se a construir medidas, econômicas, de bem-estar social, as quais ajudam a avaliar e a escolher de modo mais preciso as políticas públicas com que o governo intervém na sociedade. A concepção de Pigou é fruto de uma análise econômica das relações entre o Estado e o Mercado. Nela, faz-se prevalecer a importância da intervenção governamental, do interesse comum sobre aquele do interesse privado, ante a impossibilidade prática e concreta de uma realização da teoria ideal do reino dos fins de Kant, em que todos os indivíduos seriam perfeitamente racionais. Com Pigou, acredita-se que a ciência econômica é um novo e mais poderoso instrumento na construção de novos desenhos do mecanismo institucional que é o Estado, de modo a torná-lo mais eficiente e equitativo, na realização de uma sociedade mais justa.

\section{Conclusão}

Neste artigo, pretendeu-se completar outro artigo, ${ }^{53}$ ambos com o principal objetivo de proporcionar uma reconstrução racional do programa de pesquisa

$52 \quad$ PIGOU, A. C. The Economics of Welfare. London: Macmillan, 1932.

53 CHIAPPIN, J. R. N.; LEISTER, C. Experimento mental I: a concepção contratualista clássica, o modelo da tragédia dos comuns e as condições de emergência e estabilidade da cooperação. Hobbes, 2007. Disponível em: <http://escholarship.org/uc/item/3n07b7zq?query=chiappin>. 
sobre a política e o direito como ciência, e do seu problema associado, que é aquele das condições de emergência da cooperação entre indivíduos interagentes. $\mathrm{O}$ núcleo central desse programa é a tese de que a única entidade relevante é o indivíduo racional e autointeressado, juntamente com a tese de que o modelo de racionalidade é aquele do modelo de escolha racional. A tese seguida neste artigo é de que há progressividade entre a solução dos contratualistas, com o desenho do mecanismo institucional do Estado de Direito e do indivíduo como pessoa, e a dos utilitaristas, do Estado Democrático e Social de Direito e do indivíduo como cidadão participante dos negócios do Estado. O problema da estabilidade é mais central para os utilitaristas. $O$ formato da concepção do Estado como um mecanismo combinando a democracia liberal com a economia de mercado é o termo da progressividade do programa clássico. Se há continuidade entre os subprogramas, há também rupturas importantes, particularmente, na explicação e justificação teórica de suas soluções. Sem a compreensão da relação entre a epistemologia e a política, ficam obscuras as continuidades e rupturas entre os dois subprogramas.

São Paulo, janeiro de 2014.

\section{Referências}

BENTHAM, J. Uma introdução aos princípios da moral e da legislação. São Paulo: Abril, 1974. (Coleção Os Pensadores).

. The works of Jeremy Bentham. Bowring, John. Bristol: Thoemmes Press, 1843.

BOBBIO, Norberto. Hobbes. São Paulo: Campus, 1991.

CHIAPPIN, J. R. N. Transição de fase no modelo de Ising com campo transverso. 1979. Dissertação (Mestrado) - Instituto de Física, Universidade de São Paulo, São Paulo. 1979.

CHIAPPIN, J. R. N. Racionalidade, decisão, solução de problemas e o programa racionalista. Ciência \& Filosofia, v. 5, p. 155-219, 1996.

. Duhem's theory of Science: an interplay between philosophy and history of science. 1989. Ph.D thesis - University of Pittsburgh, U.S.A. Ann Arbor: University Microfilms International, 1989.

CHIAPPIN, J. R. N.; LEISTER, C. Experimento mental I: a concepção contratualista clássica, o modelo da tragédia dos comuns e as condições de emergência e estabilidade da cooperação. Hobbes, 2007. Disponível em: <http://escholarship.org/uc/item/3n07b7zq?query=chiappin>.

CHIAPPIN, J. R. N.; OLIVEIRA, M. The emergence of cooperation among interacting individuals. Physical Review E., v. 59, n. 6, p. 6.419-6.421, 1999.

COASE, R. H. The firm, the market and the law. Chicago: The University of Chicago Press, 1988. 
DESCARTES, R. Regras para a direção do espírito. Lisboa: Estampa, 1971.

. Meditações. São Paulo: Nova Cultural, 1996a. (Coleção Os Pensadores).

. Discurso sobre o método. São Paulo: Nova Cultural, 1996b. (Coleção Os Pensadores).

HAUSMAN, D. M.; McPHERSON, M. S. Economic analysis and moral philosophy. Cambridge: Cambridge University Press, 1996.

HOBBES, T. The elements of law. London: Frank Cass, 1969.

. Leviatã. São Paulo: Abril, 1974. (Coleção Os Pensadores).

. De cive. Petrópolis: Vozes, 1993.

Leviatã: ou a matéria, forma e poder de um Estado Eclesiástico e Civil. São Paulo: Ícone,

2000.

. Behemoth ou o Longo Parlamento. Belo Horizonte: UFMG, 2001.

. Os elementos da lei natural e política. São Paulo: Ícone, 2002.

HUME, D. Ensaios morais, políticos e literários. São Paulo: Abril, 1973. (Coleção Os Pensadores). . A treatise of human nature. London: Oxford University Press, 1980.

. Ensaios morais, políticos e literários. Rio de Janeiro: TopBooks, 2004.

KANT, I. Fundamentação metafísica dos costumes. São Paulo: Abril, 1974. (Coleção Os Pensadores).

KELSEN, H. Teoria pura do direito. São Paulo: Martins Fontes, 1994.

KOORSGARD, C. M. The sources of normativity. Cambridge: Cambridge University Press, 2000.

LAKATOS, I. O falseamento e a metodologia dos programas de pesquisa científica. In:

MUSGRAVE, A. (Org.). A crítica e o desenvolvimento do conhecimento. São Paulo: Cultrix/ EDUSP, 1971. p. 109-243.

LEISTER, C. Programa de pesquisa da racionalidade e teoria da decisão: racionalidade e teoria da decisão adaptativa. 2001. Dissertação (Mestrado) - Faculdade de Filosofia, Letras e Ciências Humanas, Universidade de São Paulo, São Paulo.

Social choice \& public choice: o problema da agregação e o cálculo das regras de decisão coletiva como fórmulas de alocação/distribuição de recursos. 2005. Tese (Doutorado) - Faculdade de Filosofia, Letras e Ciências Humanas, Universidade de São Paulo, São Paulo.

LEISTER, C.; CHIAPPIN, J. R. N. Experimento mental I. A concepção contratualista clássica, o modelo da tragédia dos comuns e as condições da emergência e da estabilidade da cooperação: Locke, Rousseau e Kant. 2007. Disponível em: <http://escholarship.org/uc/ item/81m032w6?query=chiappin $>$. 
LEISTER, C.; CHIAPPIN, J. R. N. Reconstrução racional do racionalismo crítico Popperiano II. Ciência e Filosofia, 2008.

LOCKE, J. Segundo tratado sobre o governo. São Paulo: Abril Cultural, 1983. (Coleção Os Pensadores).

MACPHERSON, C. B. A teoria política do individualismo possessivo: de Hobbes a Locke. Rio de Janeiro: Paz e Terra, 1979.

NEWTON, I. Opticks. New York: Dover Science, 1952.

NOZICK, R. Anarchy, State and utopia. New York: Basic Books, 1974.

PIGOU, A. C. The Economics of Welfare. London: Macmillan, 1932.

POLANYI, K. The great transformation. The political and economic origins of our time. London: Beacon Press, 1971.

POSNER, R. The economics of justice. Cambridge: Harvard University Press, 1983.

RAWLS, J. Uma teoria da justiça. São Paulo: Martins Fontes. 2002.

ROUSSEAU, J.-J. O contrato social: princípios do direito político. São Paulo: Martins Fontes, 1999a.

. Discurso sobre a origem e os fundamentos da desigualdade entre os homens. São Paulo: Martins Fontes, 1999b.

SANTILLÁN, J. F. F. Hobbes y Rousseau: entre la autocracia y la democracia. México: Fondo de Cultura Económica, 1988.

. Locke y Kant: ensayos de filosofía política. México: Fondo de Cultura Económica, 1992.

SKYRMS, B. The stag hunt and the evolution of the social structure. Cambridge: Cambridge University Press, 2003.

SMITH, A. Uma investigação sobre a natureza e causa das riquezas das nações. Curitiba: Hemus, 2001.

VARIAN, H. Microeconomia. São Paulo: Campus, 2007. 